\title{
Free Radical-Scavenging, Anti-Inflammatory, and Antibacterial Activities of Water and Ethanol Extracts Prepared from Compressional-Puffing Pretreated Mango (Mangifera indica L.) Peels
}

\author{
Chun-Yung Huang $\mathbb{D}^{\text {D }}$, Chia-Hung Kuo, Chien-Hui Wu, Ai-Wei Kuan, Hui-Ru Guo, \\ Yu-Hua Lin, and Po-Kai Wang \\ Department of Seafood Science, National Kaohsiung University of Science and Technology, Kaohsiung, Taiwan \\ Correspondence should be addressed to Chun-Yung Huang; cyhuang@webmail.nkmu.edu.tw
}

Received 20 September 2017; Revised 16 January 2018; Accepted 28 January 2018; Published 21 February 2018

Academic Editor: Alberto Fiore

Copyright (C) 2018 Chun-Yung Huang et al. This is an open access article distributed under the Creative Commons Attribution License, which permits unrestricted use, distribution, and reproduction in any medium, provided the original work is properly cited.

\begin{abstract}
During the processing of mango, a huge amount of peel is generated, which is environmentally problematic. In the present study, a compressional-puffing process was adopted to pretreat the peels of various mango cultivars, and then the bioactive compounds of mango peels were extracted by water or ethanol. The phenolic compound compositions as well as the free radical-scavenging, antiinflammatory, and antibacterial activities of water extract (WE) and ethanol extract (EE) from nonpuffed (NP) and compressionalpuffed (CP) mango peels were further evaluated. It was found that compressional-puffing could increase the yield of extracts obtained from most mango varieties and could augment the polyphenol content of extracts from Jinhwang and Tainoung number 1 (TN1) cultivars. The WE and EE from TN1 exhibited the highest polyphenol content and the greatest free radical-scavenging activities among the mango cultivars tested. Seven phenolic compounds (gallic acid, pyrogallol, chlorogenic acid, $p$-hydroxybenzoic acid, $p$-coumaric acid, ECG, and CG) were detected in CPWE (compressional-puffed water extract) and CPEE (compressionalpuffed ethanol extract) from TN1, and antioxidant stability of both CPWE and CPEE was higher than that of vitamin C. Further biological experiments revealed that CPEE from TN1 possessed the strongest anti-inflammatory and antibacterial activities, and thus it is recommended as a multibioactive agent, which may have applications in the food, cosmetic, and nutraceutical industries.
\end{abstract}

\section{Introduction}

Mango (Mangifera indica L.) is recognized as one of the most economically productive fruits in tropical and subtropical areas throughout the globe. Mango has excellent nutritional value and health-promoting properties. A variety of studies have been performed showing high concentrations of antioxidants including ascorbic acid, carotenoids, and phenolic compounds in mango [1]. Mango fruit is the main edible part and is usually processed into various products such as puree, nectar, jam, leather, pickles, chutney, frozen mango, dehydrated products, and canned slices. During the processing of mango, a huge amount of peel is generated, which constitutes approximately $15-20 \%$ of the mango fruit [2]. Mango peel is a waste by-product, and its disposal may have a substantial impact on the environment. Previous studies reported that mango peel contains a variety of valuable compounds such as polyphenols, carotenoids, enzymes, and dietary fiber [2]. Extracts from mango peel also exhibit antioxidant activity [3], anti-inflammatory activity [4], protection against membrane protein degradation and morphological changes in rat erythrocytes caused by hydrogen peroxide $\left(\mathrm{H}_{2} \mathrm{O}_{2}\right)$ [5], antibacterial activity [6], and anticancer activity [7]. Hence, the utilization of mango peels may be an economical means of ameliorating the problem of waste disposal from mango production factories, as well as converting a by-product into material for food, cosmetic, and pharmaceutical industrial usages.

Free radicals, including superoxide anion radical $\left(\mathrm{O}_{2}{ }^{--}\right)$, hydroperoxyl radical $\left(\mathrm{HO}_{2}^{\circ}\right)$, hydroxyl radical $\left(\mathrm{HO}^{\circ}\right)$, 
peroxyl radical $\left(\mathrm{ROO}^{\circ}\right)$, and alkoxyl radical $\left(\mathrm{RO}^{\circ}\right)$, are defined as any molecules or atoms with one or more unpaired electrons and are often involved in human diseases [8]. Many studies have shown that free radicals in living organisms cause oxidative damage to different molecules such as lipids, proteins, and nucleic acids and these are involved in the interaction phases of many diseases such as cancer, atherosclerosis, respiratory ailments, and even neuronal death [9]. Antioxidants are substances that delay or prevent the oxidation of cellular oxidisable substrates. They exert their effect by scavenging reactive oxygen species (ROS) or preventing the generation of ROS [10]. Synthetic antioxidant compounds such as butylated hydroxytoluene (BHT) and butylated hydroxyanisole (BHA) have potent antioxidant activity and are commonly used in processed foods. However, they have been restricted because of their carcinogenicity and other toxic properties [11, 12]. Thus, in recent years, there has been considerable interest in natural antioxidants derived from biological materials because of their presumed safety and potential nutritional and therapeutic value.

A large number of publications have suggested that fruit polyphenols are related to immunomodulatory and antiinflammatory properties via in vitro and animal studies [13]. Inflammation is a complicated physiological phenomenon that occurs when the immune system in the body is activated to counter threats such as injury, infection, and stress. Macrophages often play a unique role in the immune system because they not only elicit an innate immune response but also act as effector cells in inflammation and infection. When macrophages encounter bacterial endotoxin lipopolysaccharide (LPS), they can be stimulated to generate a variety of inflammatory mediators such as nitric oxide (NO), tumor necrosis factor- $\alpha$ (TNF- $\alpha$ ), interleukin- $1 \beta$ (IL$1 \beta$ ), IL-6, prostaglandin E2 (PGE2), and adhesion molecules to help eradicate the bacterial assault [14]. Generally, substances with inhibitory effects on the expression and activity of enzymes (e.g., inducible NO synthase (iNOS)) involved in the generation of inflammatory mediators such as $\mathrm{NO}$ in the mouse macrophage-like cell line RAW 264.7 are considered to possess immunomodulatory activity [15]. Since a variety of polyphenols exist in mango peels, further research on the use of mango peel extracts as immunomodulatory or antiinflammatory agents is warranted.

Antibacterial agents are the synthetic or natural compounds that interfere with the growth and division of bacteria. A number of studies have shown that pathogenic microorganisms in humans and various animal species have developed resistance to drugs. This drug resistance is due to the random or otherwise inappropriate usage of commercial antimicrobial agents. As such, there is an urgent need for new antibacterial agents. In addition, synthetic antibiotics have been known to induce side effects such as the appearance of resistant bacteria, skin irritation, organ damage, and immunohypersensitivity [16]. Accordingly, many studies have attempted to develop new agents with high antibacterial activity but with fewer or possibly even no side effects. There is a particular demand for antibacterial compounds from natural resources [17]. Plants produce a range of antimicrobial compounds in various parts such as bark, stalk, leaves, roots, flowers, pods, seeds, stems, hull, latex, and fruit rind [6]. Fruit peel is the outer covering of a fruit, which functions as a physical barrier. It also serves as a chemical barrier by virtue of the presence of many antimicrobial constituents, which protect the fruit from exposure to external pathogens or other factors that may tend to decrease the quality of the fruit. Therefore, fruit peels are good sources for obtaining natural antibacterial agents.

Bioactive compounds in mango peel are generally extracted via the following methods: extraction with $80 \%$ ethanol by sonication for 3 days at room temperature [18]; extraction performed three times with methanol, for $3 \mathrm{~h}$ per time [19]; extraction with $95 \%$ ethanol three times, $72 \mathrm{~h}$ per time [20]; extraction with acetone or ethyl acetate for up to $20 \mathrm{~h}$ [21-23]; extraction by microwave-assisted method $[24,25]$; or extraction with supercritical $\mathrm{CO}_{2}$, followed by pressurized ethanol [26]. However, these methods generally involve the use of a large volume of solvents, require a long extraction time, consume a lot of energy, are costly, and sometimes are not eco-friendly. The present study builds upon on the research reported in our previous investigation [27]. In brief, we previously developed a compressional-puffing process that has been successfully implemented to increase the extraction yield of fucoidan from brown seaweed [27, 28] and augment the extraction yields of total phenolics and total flavonoids from pine needles [29, 30]. Compressionalpuffing can be utilized as a pretreatment step to disrupt the cellular structure of samples, thereby better enabling the release of bioactive compounds by solvent extraction [27]. In this study, compressional-puffing was utilized for pretreatment of mango peels, and water extract (WE) and ethanol extract (EE) extracted from nonpuffed (NP) and compressional-puffed (CP) mango peels were compared. The phenolic compound composition and the free radicalscavenging, anti-inflammatory, and antibacterial activities of WE and EE from mango peels were also evaluated. To the best of the authors' admittedly limited knowledge, this is the first study to elucidate the free radical-scavenging, anti-inflammatory and antibacterial activities of WE and EE extracted from compressional-puffed mango peels. The recovered WE and $\mathrm{EE}$ are expected to possess multifunctional activities providing a wide range of benefits. The utilization of mango peel will also help to play a role in minimizing the generation of waste worldwide.

\section{Materials and Methods}

2.1. Materials. Folin-Ciocalteu's phenol reagent, gallic acid, protocatechuic acid, chlorogenic acid, $p$-hydroxybenzoic acid, pyrogallol, caffeic acid, mangiferin, epicatechin, $p$ coumaric acid, ferulic acid, epicatechin gallate (ECG), catechin gallate (CG), ellagic acid, rutin, quercetin, kaempferol, homogentisic acid, tannic acid, vanillic acid, 2,2-diphenyl-1-picrylhydrazyl (DPPH), sodium nitrite, LPS, dimethyl sulfoxide (DMSO), and 2,2' -azino-bis(3-ethylbenzothiazoline-6-sulphonic acid) diammonium salt (ABTS) were purchased from Sigma-Aldrich (St. Louis, MO, USA). 3-(4, 5-Dimethylthiazol-2-yl)-2,5-diphenyltetrazolium bromide 


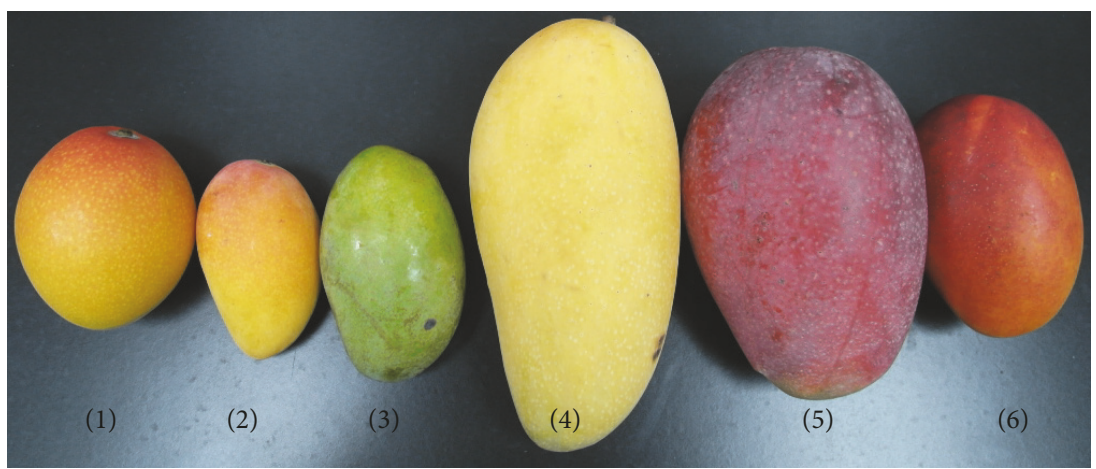

Figure 1: Appearance of various Taiwanese mango varieties. (1) Haden; (2) Tainoung number 1; (3) Tu; (4) Jinhwang; (5) Yuwen; (6) Irwin.

(MTT) was purchased from Calbiochem (San Diego, CA, USA). Dulbecco's modified Eagle's medium (DMEM), trypsin/EDTA, fetal bovine serum (FBS), penicillin, and streptomycin were purchased from Gibco Laboratories (Grand Island, NY, USA). Methanol, acetic acid, and potassium persulfate were obtained from Nihon Shiyaku Industries, Ltd. (Tokyo, Japan). All other reagents if not declared were purchased from Sigma-Aldrich (St. Louis, MO, USA) and were all of analytical grade.

2.2. Mango Fruits and Peels. Six mango cultivars, produced in Tainan City, Taiwan, were utilized in this study. The varieties, namely, Jinhwang, Tainoung number 1 (TN1), Irwin, Yuwen, Haden, and $\mathrm{Tu}$ (Figure 1), were collected from a local grocery market in Xinhua District, Tainan City, Taiwan. The fruits were used after they had completed ripening. Samples of peels were separated manually from six varieties of mango fruits and were then oven-dried and stored in aluminum bags at $4^{\circ} \mathrm{C}$ until use.

2.3. Compressional-Puffing Procedure. A compressionalpuffing method $[27,28,31]$ with minor modification was adopted to pretreat mango peels. In brief, the dried peel samples were crumbled and sieved using a 20-mesh screen. The portion retained by the screen was collected and then compressional-puffed using a continuous compressionalpuffing machine with the temperature set at $220^{\circ} \mathrm{C}$. The corresponding mechanical compression pressure and steam pressure levels inside the chamber are listed in Table 1. After the compressional-puffing, the peel samples were ground into fine particles and stored at $4^{\circ} \mathrm{C}$ for further extraction experiments.

2.4. Extraction Procedure. We followed the methods of Yang et al. (2017) [28]. Briefly, the nonpuffed and compressionalpuffed peel samples were pulverized and sieved using a 20 -mesh screen. The portion passed through the screen was collected and extracted by $95 \%$ ethanol $(\mathrm{w} / \mathrm{v}=1: 10)$ for $4 \mathrm{~h}$ at $25^{\circ} \mathrm{C}$ with shaking. The resultant solution was then centrifuged at $9,170 \times \mathrm{g}$ for $10 \mathrm{~min}$ and the supernatant was collected. NPEE (nonpuffed ethanol extract) and CPEE (compressional-puffed ethanol extract) were thus obtained after oven-drying the supernatant at $40^{\circ} \mathrm{C}$. In addition, the precipitates after $95 \%$ ethanol extraction were further extracted by double-distilled water $(\mathrm{w} / \mathrm{v}=1: 10)$ for $1 \mathrm{~h}$ at $70^{\circ} \mathrm{C}$ with shaking. Then the mixture was centrifuged at $9,170 \times \mathrm{g}$ for $10 \mathrm{~min}$ and the supernatant was collected. NPWE (nonpuffed water extract) and CPWE (compressional-puffed water extract) were obtained after oven-drying the supernatant at $50^{\circ} \mathrm{C}$. All dried extracts were milled to fine particles and stored at $4^{\circ} \mathrm{C}$ for further analyses. The combined compressional-puffing pretreatment and extraction process is depicted in detail in Figure 2. The extraction yield was calculated using the following equation:

$$
\text { extraction yield }(\%)=\left(g_{\mathrm{A}} / g_{\mathrm{B}}\right) \times 100 \text {, }
$$

where $g_{\mathrm{A}}$ represents the dry mass weight of the extract and $g_{\mathrm{B}}$ is the weight of the mango peel sample on a dry basis.

2.5. Determination of Polyphenol Content. Polyphenol content was estimated by the Folin-Ciocalteu colorimetric method based on the procedure of Singleton and Rossi (1965) [32] and using gallic acid as the standard agent.

2.6. High-Performance Liquid Chromatography (HPLC) Analysis of Total Phenolic Compound Composition. The separation of total phenolic compounds was performed by the method of Schieber et al. (2000) [33] and using a Shimadzu HPLC system (Shimadzu, Kyoto, Japan) equipped with a UV-vis detector. A reversed-phase Inspire C18 column $(250 \mathrm{~mm}$ $\times 4.6 \mathrm{~mm}$, id $5 \mu \mathrm{m}$ ) purchased from Dikma Technologies (USA) was used for all chromatographic separations. The column was operated at $25^{\circ} \mathrm{C}$. The mobile phase consisted of $2 \%(\mathrm{v} / \mathrm{v})$ acetic acid in water (eluent $\mathrm{A}), 0.5 \%$ acetic acid in water, and acetonitrile $(50: 50, \mathrm{v} / \mathrm{v}$; eluent $\mathrm{B})$. The gradient program was as follows: $20-55 \% \mathrm{~B}(50 \mathrm{~min}), 55-100 \% \mathrm{~B}$ (10 $\mathrm{min})$, and $100-20 \% \mathrm{~B}(5 \mathrm{~min})$. The injection volume of all samples was $20 \mu \mathrm{l}$. The spectra were monitored at $280 \mathrm{~nm}$ and performed at a flow rate of $1 \mathrm{ml} / \mathrm{min}$. Gallic acid, pyrogallol, protocatechuic acid, chlorogenic acid, $p$ hydroxybenzoic acid, caffeic acid, mangiferin, epicatechin, p-coumaric acid, ferulic acid, ECG, CG, ellagic acid, rutin, quercetin, kaempferol, homogentisic acid, tannic acid, and vanillic acid were used as standards for HPLC analyses.

2.7. DPPH Radical-Scavenging Activity. The scavenging activity of the DPPH radical in the samples was determined 
TABLE 1: Process variables for compressional-puffing and extraction and extraction yields for various Taiwanese mango peel extracts.

\begin{tabular}{|c|c|c|c|c|c|}
\hline \multicolumn{2}{|l|}{ Operational variables } & \multirow{2}{*}{$\begin{array}{c}\text { NPWE } \\
0\end{array}$} & \multirow{2}{*}{$\begin{array}{c}\text { CPWE } \\
5\end{array}$} & \multirow{2}{*}{$\begin{array}{c}\text { NPEE } \\
0\end{array}$} & \multirow{2}{*}{$\begin{array}{c}\text { CPEE } \\
5\end{array}$} \\
\hline Mechanical compression & Pressure $\left(\mathrm{kg} / \mathrm{cm}^{2}\right)$ & & & & \\
\hline rvecnamical compression & Number of compression times & 0 & 3 & 0 & 3 \\
\hline \multirow{3}{*}{ Puffing } & Temperature $\left({ }^{\circ} \mathrm{C}\right)$ & 0 & 220 & 0 & 220 \\
\hline & Pressure $\left(\mathrm{kg} / \mathrm{cm}^{2}\right)$ & 0 & 11 & 0 & 11 \\
\hline & Time (sec) & 0 & 10 & 0 & 10 \\
\hline \multirow{3}{*}{ Pretreatment } & Solvent & 95\% $\mathrm{EtOH}$ & $95 \% \mathrm{EtOH}$ & $\mathrm{NA}^{*}$ & NA \\
\hline & Temperature $\left({ }^{\circ} \mathrm{C}\right)$ & 25 & 25 & NA & NA \\
\hline & Time (h) & 4 & 4 & NA & NA \\
\hline \multirow{3}{*}{ Extraction } & Solvent & $\mathrm{ddH}_{2} \mathrm{O}$ & $\mathrm{ddH}_{2} \mathrm{O}$ & 95\% $\mathrm{EtOH}$ & $95 \% \mathrm{EtOH}$ \\
\hline & Temperature $\left({ }^{\circ} \mathrm{C}\right)$ & 70 & 70 & 25 & 25 \\
\hline & Time $(\mathrm{h})$ & 1 & 1 & 4 & 4 \\
\hline \multicolumn{2}{|c|}{ Extraction yield of extract $(\%)^{* *}$} & NPWE & CPWE & NPEE & CPEE \\
\hline \multicolumn{2}{|l|}{ Jinhwang cultivar } & $33.5 \pm 0.4^{\mathrm{cBC} * * *}$ & $36.6 \pm 2.3^{\mathrm{bC}}$ & $23.4 \pm 1.2^{\mathrm{bA}}$ & $30.2 \pm 1.0^{\mathrm{cB}}$ \\
\hline \multicolumn{2}{|l|}{ Tainoung number 1 cultivar } & $29.5 \pm 1.2^{\mathrm{bA}}$ & $34.8 \pm 1.0^{\mathrm{bB}}$ & $29.2 \pm 0.7^{\mathrm{dA}}$ & $33.7 \pm 0.9^{\mathrm{dB}}$ \\
\hline \multicolumn{2}{|l|}{ Irwin cultivar } & $30.9 \pm 0.9^{\mathrm{bcB}}$ & $40.0 \pm 2.2^{\mathrm{bC}}$ & $22.6 \pm 0.3^{\mathrm{bA}}$ & $29.6 \pm 0.4^{\mathrm{cB}}$ \\
\hline \multicolumn{2}{|l|}{ Yuwen cultivar } & $31.2 \pm 1.4^{\mathrm{bcB}}$ & $37.0 \pm 1.8^{\mathrm{bC}}$ & $26.3 \pm 0.9^{\mathrm{cA}}$ & $37.4 \pm 1.0^{\mathrm{eC}}$ \\
\hline \multicolumn{2}{|l|}{ Haden cultivar } & $25.5 \pm 1.5^{\mathrm{aB}}$ & $28.6 \pm 2.7^{\mathrm{aB}}$ & $18.8 \pm 0.8^{\mathrm{aA}}$ & $20.4 \pm 0.5^{\mathrm{aA}}$ \\
\hline \multicolumn{2}{|l|}{ Tu cultivar } & $25.9 \pm 0.3^{\mathrm{aB}}$ & $29.1 \pm 0.1^{\mathrm{aD}}$ & $22.9 \pm 0.5^{\mathrm{bA}}$ & $27.0 \pm 0.1^{\mathrm{bC}}$ \\
\hline
\end{tabular}

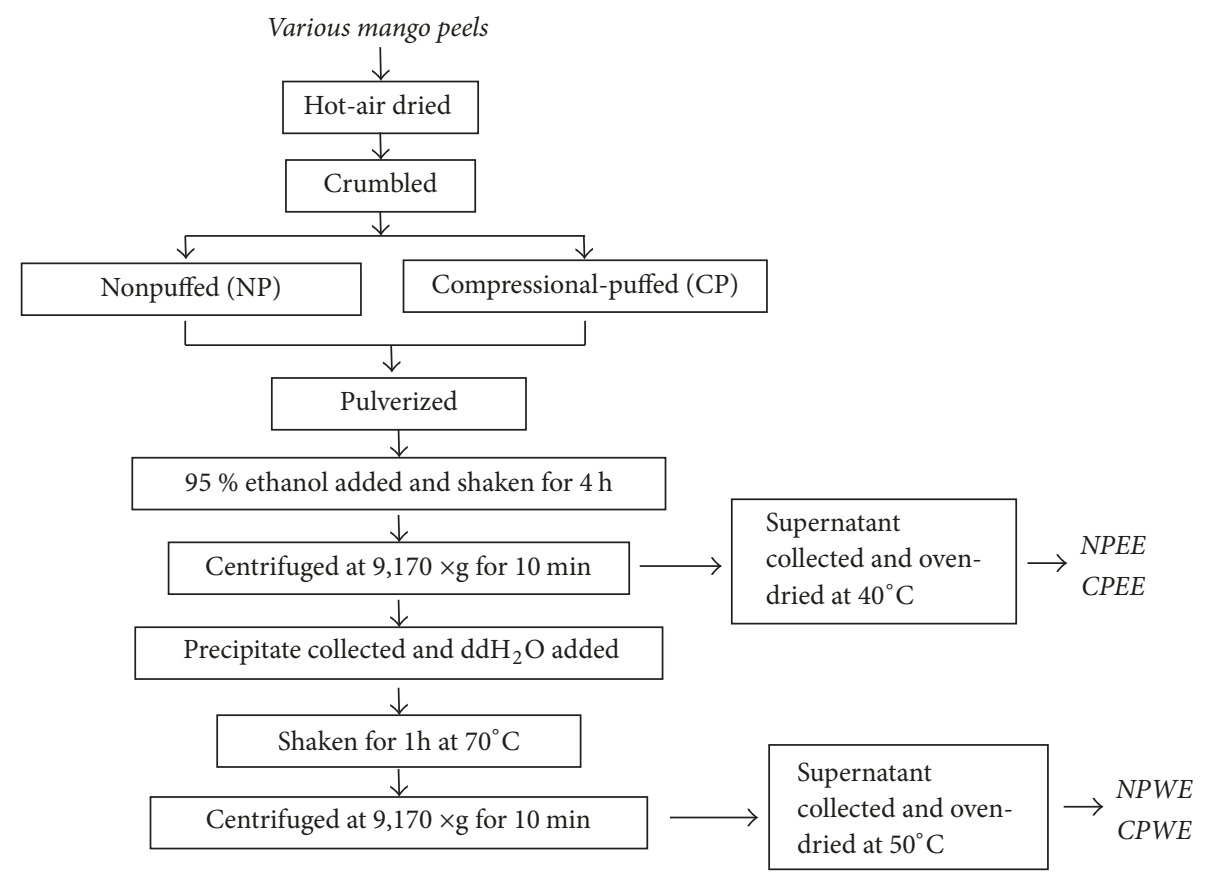

FIGURE 2: Flowchart of the compressional-puffing process and extraction methods for NPEE, CPEE, NPWE, and CPWE.

using the method described previously [28, 34]. In brief, $50 \mu \mathrm{l}$ of mango peel extract (concentrations ranging from 0 to $300 \mu \mathrm{g} / \mathrm{ml}$ for Tainoung number 1 and Haden cultivars; $0-600 \mu \mathrm{g} / \mathrm{ml}$ for Jinhwang and Tu cultivars; and 0-900 $\mu \mathrm{g} / \mathrm{ml}$ for Irwin and Yuwen cultivars) was added to $200 \mu 10.1 \mathrm{mM}$ DPPH solution (in methanol). The mixture was shaken vigorously for $1 \mathrm{~min}$ and left to stand for $30 \mathrm{~min}$ in the dark at room temperature. After the reaction, the absorbance of all sample solutions was then measured at $517 \mathrm{~nm}$ using an ELISA reader (PowerWave 340, BioTek Instruments, Winooski, VT, USA). The radical-scavenging activity was calculated as the percentage inhibition using the following equation:

$$
\mathrm{DPPH}_{\text {radical-scavenging }}(\%)=\left[1-\frac{A_{\text {sample }}}{A_{\text {control }}}\right] \times 100 \text {, }
$$


where $A_{\text {sample }}$ is the absorbance of the methanol solution of DPPH with tested samples and $A_{\text {control }}$ represents the absorbance of the methanol solution of DPPH without the sample.

2.8. ABTS Radical Cation-Scavenging Activity. The ABTS radical cation-scavenging activity was performed according to the method described previously $[28,34]$. The ABTS ${ }^{\circ+}$ solution was produced by mixing $5 \mathrm{ml}$ of $7 \mathrm{mM}$ ABTS solution with $88 \mu \mathrm{l}$ of $140 \mathrm{mM}$ potassium persulfate and allowing the mixture to stand in the dark for $16 \mathrm{~h}$ at room temperature before use. The $\mathrm{ABTS}^{\circ+}$ solution was diluted with 95\% ethanol so that its absorbance at $734 \mathrm{~nm}$ was adjusted to $0.70 \pm 0.05$. To determine the scavenging activity, $100 \mu \mathrm{l}$ diluted $\mathrm{ABTS}^{*+}$ solution was mixed with $100 \mu \mathrm{l}$ of mango peel extract (concentrations ranging from 0 to $100 \mu \mathrm{g} / \mathrm{ml}$ for Tainoung number 1 and Haden cultivars; $0-300 \mu \mathrm{g} / \mathrm{ml}$ for Irwin, Yuwen, and Tu cultivars; and $0-500 \mu \mathrm{g} / \mathrm{ml}$ for Jinhwang cultivar) and the mixture was allowed to react at room temperature for $6 \mathrm{~min}$. After the reaction, the absorbance of all sample solutions was then measured at $734 \mathrm{~nm}$ using an ELISA reader (PowerWave 340, BioTek Instruments, Winooski, VT, USA). The blank was prepared in the same manner, except that distilled water was used instead of the sample. The scavenging activity of $\mathrm{ABTS}^{*+}$ was calculated using the following equation:

$$
\operatorname{ABTS}_{\text {radical cation-scavenging }}(\%)=\left[1-\frac{A_{\text {sample }}}{A_{\text {control }}}\right] \times 100,
$$

where $A_{\text {sample }}$ is the absorbance of ABTS with tested samples and $A_{\text {control }}$ represents the absorbance of ABTS without the sample.

2.9. Cell Line and Culture. Murine macrophage cell lines RAW 264.7 were obtained from the Bioresource Collection and Research Center, the Food Industry Research and Development Institute (FIRDI, Hsinchu, Taiwan). The cells were grown in DMEM supplemented with $10 \%$ FBS and $100 \mathrm{U} / \mathrm{ml}$ penicillin-streptomycin solution at $37^{\circ} \mathrm{C}$ in a humidified chamber with $5 \% \mathrm{CO}_{2}$. The medium was changed every two days.

2.10. Measurement of Cell Viability. The MTT assay was used to evaluate cell viability. Briefly, RAW 264.7 cells $\left(2 \times 10^{5} / \mathrm{ml}\right.$ in a 96-well plate) were plated with culture medium and incubated for $24 \mathrm{~h}$ at $37^{\circ} \mathrm{C}$, with $5 \% \mathrm{CO}_{2}$ in a humidified atmosphere. The medium was removed and fresh serum-free medium containing different concentrations of mango peel extracts (concentrations ranging from 0 to $25 \mu \mathrm{g} / \mathrm{ml}$ for CPEE of TN1 and CPWE of TN1) was added. After $24 \mathrm{~h}$ of incubation at $37^{\circ} \mathrm{C}$, with $5 \% \mathrm{CO}_{2}$, the MTT reagent $(0.1 \mathrm{mg} / \mathrm{ml})$ was added. After incubating at $37^{\circ} \mathrm{C}$ for $4 \mathrm{~h}$, the MTT reagent was removed and DMSO $(100 \mu \mathrm{l})$ was added to each well and thoroughly mixed by pipetting to dissolve the MTT-formazan crystals. The absorbance was then determined by an ELISA reader (PowerWave 340, BioTek Instruments, Winooski, VT, USA) at a wavelength of $570 \mathrm{~nm}$. The cell viability (\%) was calculated using the following equation:

$$
\text { Cell viability }(\%)=\left(\frac{T}{C}\right) \times 100,
$$

where $T$ is the absorbance in the test and $C$ is the absorbance for the control.

2.11. Measurement of Nitrite Oxide in Culture Media. RAW 264.7 cells $\left(2 \times 10^{5}\right.$ cells $\left./ \mathrm{ml}\right)$ were seeded in a 96-well flat bottom plate for $24 \mathrm{~h}$ at $37^{\circ} \mathrm{C}$ with $5 \% \mathrm{CO}_{2}$. The culture medium was removed and replaced with fresh medium containing tested samples at various concentrations prior to challenging with $1 \mu \mathrm{g} / \mathrm{ml}$ of LPS. The nitrite concentration was measured in the culture supernatant after $24 \mathrm{~h}$ of coincubation. In brief, $50 \mu \mathrm{l}$ of the cultured supernatants was added in the 96well plate and $100 \mu \mathrm{l}$ of Griess reagent was added to each well and allowed to stand for $10 \mathrm{~min}$ at room temperature. The absorbance at $540 \mathrm{~nm}$ was measured using an ELISA reader (PowerWave 340, BioTek Instruments, Winooski, VT, USA), and the quantification of nitrite was standardized with $\mathrm{NaNO}_{2}$ at $0-100 \mu \mathrm{M}$ concentrations [35].

2.12. Zone of Inhibition. Five bacteria were tested for antibacterial activity of mango peel extracts. These were three Gramnegative bacteria (Escherichia coli ATCC 11775, Salmonella typhimurium ATCC 13311, and Vibrio parahaemolyticus ATCC 17802) and two Gram-positive bacteria (Staphylococcus aureus ATCC 12600 and Bacillus cereus ATCC 14579), which were obtained from the Culture Collection and Research Center of the Food Industry Research and Development Institute, Hsinchu, Taiwan. Antibacterial activity was measured using the standard method of diffusion disc plates on agar [36]. In brief, E. coli, S. typhimurium, S. aureus, and B. cereus were grown in tryptic soy broth (TSB) medium (Difco Laboratories, Detroit, MI, USA) and V. parahaemolyticus was grown in TSB medium $+3 \% \mathrm{NaCl}$ for $24 \mathrm{~h}$ at $37^{\circ} \mathrm{C}$, and $0.1 \mathrm{ml}$ of each culture of bacteria at proper cell density was spread on tryptic soy agar (TSA, Difco Laboratories, Detroit, MI, USA) plate surfaces (3\% $\mathrm{NaCl}$ was added to TSA for $V$. parahaemolyticus). Paper disc ( $8 \mathrm{~mm}$ in diameter) was placed on the agar medium to load $50 \mu \mathrm{l}$ containing $2 \mathrm{mg}$ of mango peel extract $(4 \%, \mathrm{w} / \mathrm{v}$, in $0.05 \mathrm{M}$ acetate buffer, $\mathrm{pH}$ 6.0). Control paper discs were prepared by infusing with $50 \mu \mathrm{l}$ Antibiotic-Antimycotic Solution (containing 10,000 units $/ \mathrm{ml}$ penicillin, $10 \mathrm{mg} / \mathrm{ml}$ streptomycin, and $25 \mu \mathrm{g} / \mathrm{ml}$ amphotericin) (Corning, Corning, NY, USA) or $50 \mu 10.05 \mathrm{M}$ acetate buffer. The plates were incubated at $37^{\circ} \mathrm{C}$ for $24 \mathrm{~h}$. After $24 \mathrm{~h}$, antibacterial activity of the extracts against the test bacteria was observed by growth-free zone of inhibition near the respective disc and the inhibition diameters were measured.

2.13. Statistical Analysis. Experiments were performed at least three times. Values represent the means \pm standard deviation (SD). Statistical analyses were done using the Statistical Package for the Social Sciences (SPSS). The results obtained were analyzed using one-way analysis of variance (ANOVA), followed by Duncan's Multiple Range tests. $p<0.05$ was considered statistically significant. Correlation analyses were performed using the square of Pearson's correlation coefficient $\left(R^{2}\right)$. 


\section{Results and Discussion}

3.1. Effects of Mango Varieties, Compressional-Puffing, and Extraction Methods on Extraction Yields of Peel Extracts. Six varieties of mango fruits, namely, Jinhwang, Tainoung number 1 (TN1), Irwin, Yuwen, Haden, and Tu, were collected from a local grocery market in Xinhua District, Tainan City, Taiwan. Samples of peels were separated manually and the peels were oven-dried till the moisture content reached 4-7\% (wet basis). The dried peel samples were crumbled and sieved using a 20 -mesh screen, and the portion retained by the screen was collected and compressional-puffed according to the technique developed previously [27]. Compressionalpuffing applies a mechanical compression force of approximately $5 \mathrm{~kg} / \mathrm{cm}^{2}$ to the sample three times before puffing, which can account for the difference between compressionalpuffing and the conventional puffing gun process. The puffing temperatures were set at $220^{\circ} \mathrm{C}$, and the corresponding pressure level inside the chamber was found to be $11 \mathrm{~kg} / \mathrm{cm}^{2}$ (Table 1). The NP and CP peel samples were ground and sieved using a 20-mesh screen. The portion passing through the screen was collected and then the bioactive compounds were extracted by either ethanol or hot water as shown in Figure 2. In the preliminary experiment, we extracted puffed peel sample directly using $70^{\circ} \mathrm{C}$ hot water and found that the extract, after being dried, exhibited a stone-like hard structure, which stuck tightly to the inner surfaces of the container and was difficult to dislodge. Thus, the $70^{\circ} \mathrm{C}$ hot water extraction condition was not adopted in the present study. After extraction, four peel extracts, namely, NPWE (nonpuffed water extract), CPWE (compressionalpuffed water extract), NPEE (nonpuffed ethanol extract), and CPEE (compressional-puffed ethanol extract), were obtained according to their puffing pretreatments and extraction methods for each mango cultivar (Figure 2). The yields of these extracts are indicated in Table 1. In the comparison of extraction yields among different mango varieties for these four extracts, it was found that the yields of extracts for the tested mango cultivars were similar, except that Haden and $\mathrm{Tu}$ cultivars had relatively lower extraction yields. Thus, the peels of Jinhwang, TN1, Irwin, and Yuwen cultivars with higher yields of extracts would have advantages for further commercial production. It was reported that compressional-puffing could primarily rupture the structure of the puffed samples and then augment the extraction yield of crude fucoidan from brown algae $[27,28]$ and increase the extraction yields of total phenolics and total flavonoids from pine needles $[29,30]$. In the present study, we also found that compressional-puffing could rupture the structure of mango peel (data not shown) and increase the extraction yields in both CPWE and CPEE as compared to NPWE and NPEE, respectively (Table 1). Therefore, compressional-puffing can also be effectively used in mango peels to facilitate the release of bioactive compounds by simple extraction operations. A comparison of the extraction yields between water and ethanol extractions revealed that water extraction tended to have higher yields of extracts as compared to ethanol extraction. A higher yield of extract has the potential for commercialized production. In addition, previous reports revealed that the composition of mango peel extract is complicated, and it may contain polyphenols, flavonoids, carotenoids, vitamin E, vitamin C, pectin, unsaturated fatty acids, and other biologically active components that positively influence health [25, 37-39]. Mango peel extract has also exhibited biological functions such as antioxidant properties $[25,39]$ and inhibition of HeLa human cervical carcinoma cell proliferation [38]. Generally, phenolic compounds are the major bioactive components of mango peels [18] and these have exhibited antioxidant activity and an antiproliferative effect on HeLa cells [25, 37-39]. Thus, the phenolic compound composition in our mango peel extracts and their effects on biological functions warrant further examination. Taken together, peel extracts from Jinhwang, TN1, Irwin, and Yuwen cultivars had higher extraction yields than those of Haden and Tu cultivars. Compressional-puffing pretreatment resulted in a worthwhile incremental increase in the extraction yields of mango peel extracts. Water extraction tended to have higher yields of extracts as compared to ethanol extraction, which would be beneficial in commercialized production. The phenolic compound composition and biological functions of mango peel extracts require further characterization.

\subsection{Polyphenol Contents and Free Radical-Scavenging Activi-} ties of Peel Extracts from Various Mango Cultivars. Phenolic compounds are reported to be the major bioactive components that exist in mango peels [18]. In the present study, four peel extracts (NPWE, CPWE, NPEE, and CPEE) from six mango cultivars were utilized to determine their polyphenol contents by the Folin-Ciocalteu colorimetric method. The results presented in Table 2 suggest that peel extracts from the TN1 cultivar possessed the highest amount of total phenolic compounds as compared to other peel extracts. Thus, it is reasonable to postulate that peel extracts of the TN1 may exhibit high biological activities, and therefore further investigation is warranted. Moreover, a comparison of the polyphenol contents between NPWE and CPWE in all mango cultivars revealed that polyphenol content of CPWE was higher than that of NPWE (Table 2), indicating that compressional-puffing could increase the polyphenol content of water extracts in all mango cultivars. However, in the case of ethanol extracts, only CPEEs from Jinhwang and TN1 had higher polyphenol contents than those of NPEEs from Jinhwang and TN1 (Table 2). Moreover, for all mango cultivars, polyphenol contents of ethanol extracts were higher than those of water extracts (Table 2), indicating that ethanol extraction was effective in the extraction of polyphenols. Polyphenols are well known to exhibit antioxidant activity due to their ability to scavenge free radicals via hydrogen donation or electron donation and the reactivity of the phenol moiety [40]. Accordingly, the antioxidant capacities of NPWE, CPWE, NPEE, and CPEE of six mango peels were characterized using DPPH and ABTS radical-scavenging assays. DPPH is a stable free radical and is widely used to evaluate the antioxidant activity in a relatively short time compared to other methods [41]. The $\mathrm{SC}_{50}$ values (concentration of mango peel extract capable of scavenging $50 \%$ of DPPH radical) of the peel extracts (NPWE, CPWE, NPEE, and CPEE) from six mango cultivars for DPPH 
TABLE 2: Polyphenol content, DPPH radical-scavenging activity, and ABTS radical cation-scavenging activity of extracts from various Taiwanese mango peels.

\begin{tabular}{|c|c|c|c|c|}
\hline Polyphenols (\%)* & NPWE & CPWE & NPEE & CPEE \\
\hline Jinhwang cultivar & $1.40 \pm 0.11^{\mathrm{aA} * * * *}$ & $2.11 \pm 0.24^{\mathrm{aB}}$ & $5.31 \pm 0.25^{\mathrm{aC}}$ & $9.13 \pm 0.16^{\mathrm{cD}}$ \\
\hline Tainoung number 1 cultivar & $15.9 \pm 0.9^{\mathrm{eA}}$ & $16.6 \pm 1.1^{\mathrm{eA}}$ & $23.5 \pm 0.4^{\mathrm{eB}}$ & $28.5 \pm 0.7^{\mathrm{eC}}$ \\
\hline Irwin cultivar & $3.09 \pm 0.18^{\mathrm{bA}}$ & $2.92 \pm 0.19^{\mathrm{aA}}$ & $7.06 \pm 0.29^{\mathrm{bC}}$ & $5.07 \pm 0.11^{\mathrm{aB}}$ \\
\hline Yuwen cultivar & $2.36 \pm 0.25^{\mathrm{bA}}$ & $4.63 \pm 0.90^{\mathrm{bB}}$ & $7.21 \pm 0.05^{\mathrm{bD}}$ & $6.26 \pm 0.05^{\mathrm{bC}}$ \\
\hline Haden cultivar & $6.41 \pm 0.20^{\mathrm{dA}}$ & $7.31 \pm 0.19^{\mathrm{cB}}$ & $18.9 \pm 0.3^{\mathrm{dD}}$ & $13.4 \pm 0.3^{\mathrm{dC}}$ \\
\hline Tu cultivar & $5.25 \pm 0.27^{\mathrm{cA}}$ & $10.1 \pm 1.6^{\mathrm{dB}}$ & $14.7 \pm 0.2^{\mathrm{cD}}$ & $13.0 \pm 0.5^{\mathrm{dC}}$ \\
\hline DPPH, SC $_{50}$ values $(\mu \mathrm{g} / \mathrm{ml})^{* *}$ & NPWE & CPWE & NPEE & CPEE \\
\hline Jinhwang cultivar & $499 \pm 7^{\mathrm{fD}}$ & $368 \pm 13^{\mathrm{fC}}$ & $197 \pm 12^{\mathrm{dA}}$ & $251 \pm 0^{\mathrm{fB}}$ \\
\hline Tainoung number 1 cultivar & $57.0 \pm 2.2^{\mathrm{aC}}$ & $67.0 \pm 2.2^{\mathrm{aD}}$ & $46.0 \pm 1.4^{\mathrm{aB}}$ & $41.7 \pm 1.3^{\mathrm{aA}}$ \\
\hline Irwin cultivar & $368 \pm 11^{\mathrm{eC}}$ & $255 \pm 2^{\mathrm{dB}}$ & $195 \pm 9^{\mathrm{dA}}$ & $222 \pm 8^{\mathrm{eA}}$ \\
\hline Yuwen cultivar & $324 \pm 3^{\mathrm{dD}}$ & $303 \pm 5^{\mathrm{eC}}$ & $165 \pm 5^{\mathrm{cA}}$ & $206 \pm 4^{\mathrm{dB}}$ \\
\hline Haden cultivar & $124 \pm 3^{\mathrm{bD}}$ & $101 \pm 5^{\mathrm{bC}}$ & $69 \pm 5^{\mathrm{bA}}$ & $86 \pm 4^{\mathrm{bB}}$ \\
\hline Tu cultivar & $183 \pm 2^{\mathrm{cD}}$ & $158 \pm 5^{\mathrm{cC}}$ & $78.3 \pm 4.9^{\mathrm{bA}}$ & $96.7 \pm 4.7^{\mathrm{cB}}$ \\
\hline Vitamin C & $11.3 \pm 0.1$ & & & \\
\hline ABTS, SC $_{50}$ values $(\mu \mathrm{g} / \mathrm{ml})^{* * *}$ & NPWE & CPWE & NPEE & CPEE \\
\hline Jinhwang cultivar & $186 \pm 0^{\mathrm{eD}}$ & $139 \pm 0^{\mathrm{eC}}$ & $70.0 \pm 0.0^{\mathrm{fB}}$ & $54.0 \pm 3.3^{\mathrm{cA}}$ \\
\hline Tainoung number 1 cultivar & $28.2 \pm 3.8^{\mathrm{aC}}$ & $23.3 \pm 0.5^{\mathrm{aB}}$ & $15.7 \pm 0.9^{\mathrm{aA}}$ & $13.0 \pm 0.8^{\mathrm{aA}}$ \\
\hline Irwin cultivar & $113 \pm 7^{\mathrm{cC}}$ & $101 \pm 6^{\mathrm{dC}}$ & $59.0 \pm 0.8^{\mathrm{eA}}$ & $76.3 \pm 2.8^{\mathrm{eB}}$ \\
\hline Yuwen cultivar & $137 \pm 2^{\mathrm{dC}}$ & $102 \pm 2^{\mathrm{dB}}$ & $52.0 \pm 0.9^{\mathrm{dA}}$ & $62.0 \pm 1.7^{\mathrm{dA}}$ \\
\hline Haden cultivar & $55.3 \pm 1.7^{\mathrm{bC}}$ & $37.3 \pm 2.4^{\mathrm{bB}}$ & $27.3 \pm 0.9^{\mathrm{cA}}$ & $30.7 \pm 1.7^{\mathrm{bA}}$ \\
\hline Tu cultivar & $115 \pm 5^{\mathrm{cD}}$ & $77.3 \pm 3.4^{\mathrm{cC}}$ & $24.7 \pm 1.3^{\mathrm{bA}}$ & $34.0 \pm 1.6^{\mathrm{bB}}$ \\
\hline Vitamin C & $3.58 \pm 0.07$ & & & \\
\hline
\end{tabular}

${ }^{*}$ Polyphenols $(\%)=\left(\mathrm{g} / \mathrm{g}_{\text {solid extract, dry basis }}\right) \times 100 .{ }^{* *} \mathrm{SC}_{50}$ values (concentration of mango peel extract capable of scavenging $50 \%$ of DPPH radical) for $\mathrm{DPPH}$ radical-scavenging of different mango peel extracts. ${ }^{* * *} \mathrm{SC}_{50}$ values (concentration of mango peel extract capable of scavenging $50 \%$ of ABTS cation radical) for ABTS radical cation-scavenging of different mango peel extracts. ${ }^{* * * *}$ Values are mean $\pm \mathrm{SD}(n=3)$; values in the same column with different letters (in a, b, c, d, e, and f) and in the same row with different letters (in A, B, C, and D) are significantly different $(p<0.05)$.

radical-scavenging activity are presented in Table 2 . As shown in Table 2, all peel extracts from TN1 exhibited the most DPPH radical-scavenging activity as compared to other mango cultivars, and the most potent was CPEE of TN1 with an $\mathrm{SC}_{50}$ value of $41.7 \pm 1.3 \mu \mathrm{g} / \mathrm{ml}$. Kim et al. (2010) reported that the $\mathrm{SC}_{50}$ value of the DPPH radical-scavenging activity of Irwin mango peel ethanol extract was about $40 \mu \mathrm{g} / \mathrm{ml}$ [18], which was similar to the $\mathrm{SC}_{50}$ value of CPEE of TN1 reported here. A comparison of the DPPH radical-scavenging activities of the CPWE group with those of the NPWE group revealed that compressional-puffing could increase the DPPH radical-scavenging activities of peel extracts (Table 2). Moreover, DPPH radical-scavenging activity of all EE groups (including NPEE and CPEE) was greater than that of the WE groups (NPWE and CPWE), which appeared to be positively correlated with the higher polyphenol amount in the EE groups as shown in Table 2. Regarding the scavenging activity of $\mathrm{ABTS}^{\bullet+}$, the relatively long-lived $\mathrm{ABTS}^{\bullet+}$ was decolorized during the reaction with hydrogen-donating antioxidant [42]. The $\mathrm{SC}_{50}$ values (concentration of mango peel extract capable of scavenging $50 \%$ of ABTS radical cation) of the peel extracts (NPEE, CPEE, NPWE, and CPWE) from six mango cultivars for ABTS radical cation-scavenging activity are also presented in Table 2. The results show that, among the extracts from six mango cultivars, peel extracts from the TN1 exhibited the most ABTS radical cation-scavenging activity, and the $\mathrm{SC}_{50}$ value for the most potent CPEE of $\mathrm{TN} 1$ was $13.0 \pm 0.8 \mu \mathrm{g} / \mathrm{ml}$. Kim et al. (2010) reported that the $\mathrm{SC}_{50}$ value of the ABTS radical cation-scavenging activity for Irwin mango peel ethanol extract was about $200 \mu \mathrm{g} / \mathrm{ml}$ [18], which was less effective in ABTS radical cation-scavenging capacity as compared to our CPEE of TN1. Regarding NPWE and CPWE, compressional-puffing could increase the ABTS radical cation-scavenging activity in CPWE of mango cultivars, which was similar to the finding for DPPH radicalscavenging activity. All EEs (including NPEE and CPEE) had greater ABTS radical cation-scavenging activity compared to WEs (including NPWE and CPWE) (Table 2). To better understand the relationship between polyphenol contents and free radical-scavenging activities of peel extracts, a correlation plot was performed and the results are shown in Figure 3. A high correlation between the polyphenol contents of peel extracts and their corresponding free radicalscavenging activities (DPPH and ABTS radical-scavenging activities) was found in NPWE, CPWE, NPEE, and CPEE, which was also consistent with previously reported observations [43]. In summary, peel extracts from the TN1 had the highest amount of total phenolic compounds and possessed the most DPPH and ABTS free radical-scavenging activities. For all water extracts, compressional-puffing had a tendency to increase the contents of total phenolic compounds in CPWEs and resulted in an incremental increase in free 


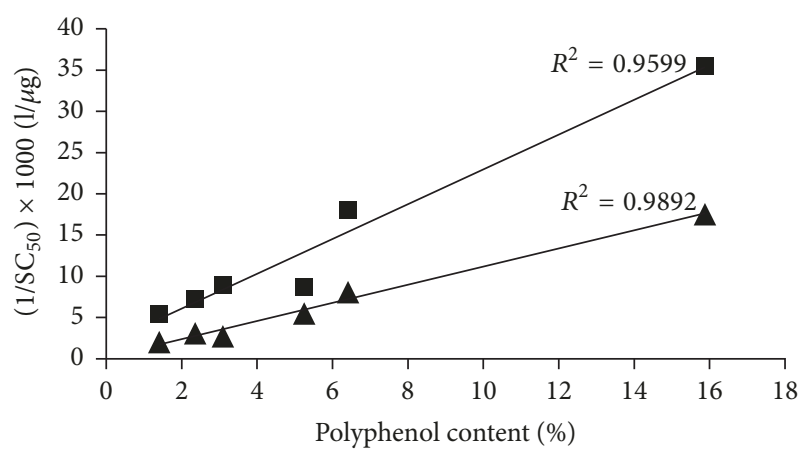

$\Delta \mathrm{DPPH}$

- ABTS

(a)

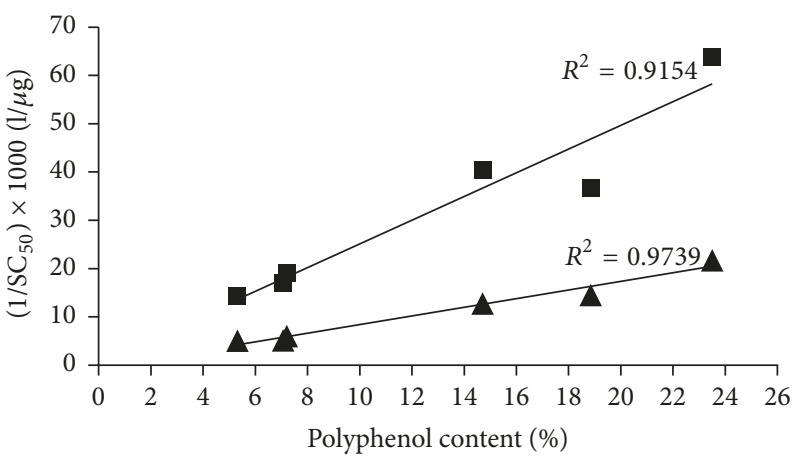

$\triangle \mathrm{DPPH}$

- ABTS

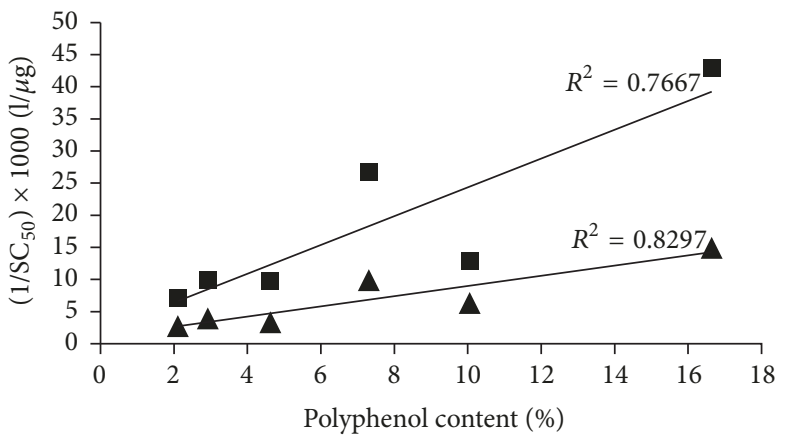

А $\mathrm{DPPH}$

- ABTS

(b)

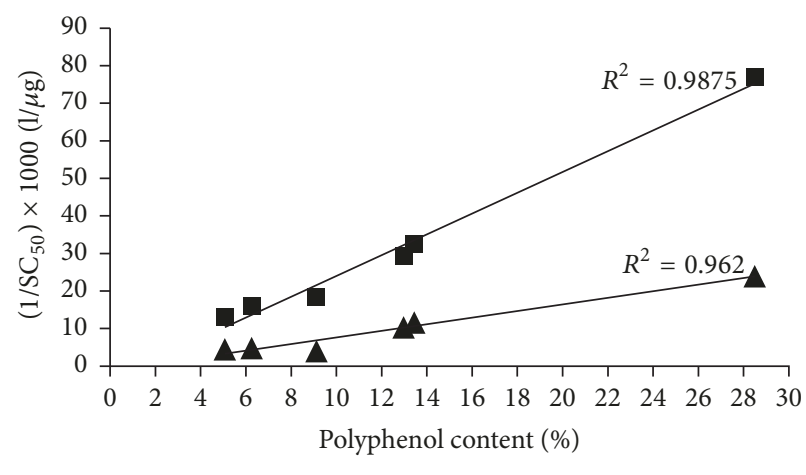

A $\mathrm{DPPH}$

aBTS

(c)

(d)

FIGURE 3: Association between polyphenol content and DPPH/ABTS radical-scavenging activities of mango peel extracts. (a) NPWE; (b) CPWE; (c) NPEE; (d) CPEE. SC $_{50}$ : concentration for scavenging $50 \%$ of DPPH or ABTS free radicals.

radical-scavenging activities as compared to NPWEs. For all ethanol extracts, only CPEE of TN1 had a higher content of total phenolic compounds and possessed higher free radical-scavenging activities as compared to NPEE of TN1. Moreover, for all extracts, ethanol extracts generally had a higher amount of total phenolic compounds and caused greater free radical-scavenging activities as compared to water extracts. Therefore, in summary, both CPWE and CPEE of the TN1 cultivar warrant further analyses of the phenolic compound composition and storage stability of their antioxidant capacity, as well as their anti-inflammatory and antibacterial activities.

3.3. Analysis of Phenolic Compound Composition, Storage Stability of Antioxidant Capacity, Anti-Inflammatory Activity, and Antibacterial Activity in CPWE and CPEE of TN1 Cultivar. Peel extracts of TN1 cultivar have the highest amount of total phenolic compounds and the most free radical-scavenging activities. Moreover, CPWE and CPEE from TN1 had higher extraction yields and greater polyphenol contents as compared to NPWE and NPEE from TN1. Therefore, the phenolic compound composition of CPWE and CPEE from TN1 was analyzed by RP-HPLC coupled with UV-vis detector. The results are shown in Figure 4 and Table 3. In Figure 4, it can be seen that seven phenolic compounds, namely, gallic
TABLE 3: Phenolic compound composition in the CPWE and CPEE of Tainoung number 1 cultivar.

\begin{tabular}{lcc}
\hline \multirow{2}{*}{ Compound } & \multicolumn{2}{c}{ Tainoung number 1 cultivar } \\
& CPWE $(\mathrm{mg} / 100 \mathrm{~g})^{*}$ & CPEE $(\mathrm{mg} / 100 \mathrm{~g})$ \\
\hline -Hydroxybenzoic acid & $1863 \pm 318$ & $3313 \pm 2$ \\
Gallic acid & $579 \pm 72$ & $1052 \pm 1$ \\
Pyrogallol & $566 \pm 55$ & $930 \pm 90$ \\
Chlorogenic acid & $125 \pm 8$ & $245 \pm 7$ \\
Catechin gallate (CG) & $125 \pm 43$ & $189 \pm 52$ \\
$p$-Coumaric acid & $68.9 \pm 9.4$ & $131 \pm 0$ \\
Epicatechin gallate (ECG) & $32.0 \pm 3.9$ & $50.8 \pm 7.0$ \\
\hline
\end{tabular}

${ }^{*}$ The concentration of phenolic compound is expressed as $\mathrm{mg} / 100 \mathrm{~g}$ peel weight, dry basis.

acid, pyrogallol, chlorogenic acid, $p$-hydroxybenzoic acid, $p$ coumaric acid, ECG, and CG, were tentatively identified in CPWE and CPEE of TN1 by HPLC analysis. Table 3 shows the quantitative data of phenolic compound composition in the CPWE and CPEE of TN1. It was found that both CPWE and CPEE of TN1 contained large amounts of $p$ hydroxybenzoic acid, gallic acid, and pyrogallol and smaller amounts of chlorogenic acid, CG, $p$-coumaric acid, and ECG. A comparison of the phenolic compound composition in 


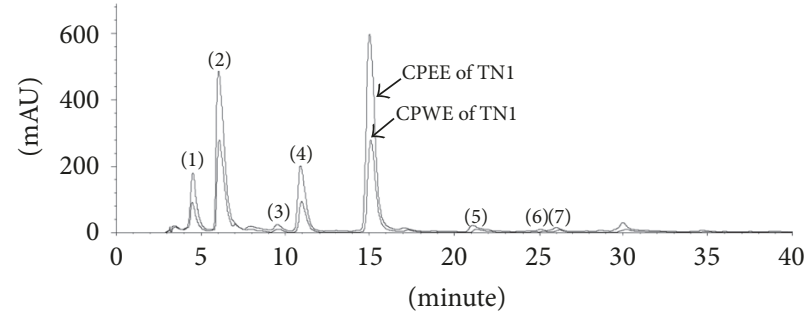

(a)

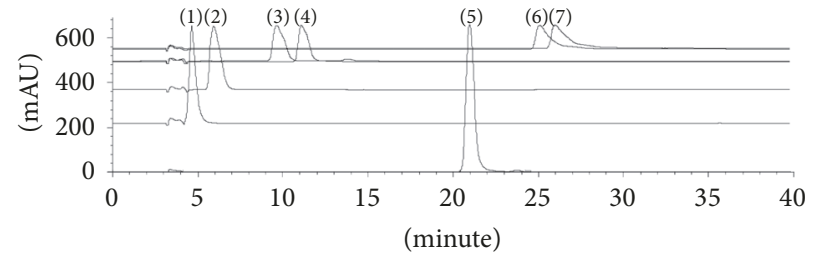

(b)

FIGURE 4: (a) High-performance liquid chromatography of peel extracts (CPWE and CPEE) of Tainoung number 1 cultivar; (b) highperformance liquid chromatography of polyphenol standards: gallic acid (1), pyrogallol (2), chlorogenic acid (3), p-hydroxybenzoic acid (4), p-coumaric acid (5), ECG (6), and CG (7).

CPWE and CPEE revealed that CPEE of TN1 had greater amounts of $p$-hydroxybenzoic acid, gallic acid, pyrogallol, chlorogenic acid, CG, $p$-coumaric acid, and ECG than those of CPWE (Table 3). These results are consistent with the data shown in Table 2, which illustrates that CPEE of TN1 has higher total phenolic compounds compared to CPWE of TN1. We found that $p$-hydroxybenzoic acid was the predominant phenolic compound detected (up to $3313 \pm 2 \mathrm{mg} / 100 \mathrm{~g}$ peel weight, dry basis) in CPEE of TN1, and the results were also supported by other studies reporting that $p$-hydroxybenzoic acid could be detected in the extract of mango cultivar [44]. The concentrations of gallic acid for CPWE and CPEE of TN1 were recorded as $579 \pm 72$ and $1052 \pm 1 \mathrm{mg} / 100 \mathrm{~g}$ peel weight, dry basis, respectively. These data are comparably higher than those reported previously for the ethanol extract of mango peel, with an average gallic acid concentration of $152.20 \pm$ $0.14 \mathrm{mg} / 100 \mathrm{~g}$ mango peel, dry weight [45]. Previous studies suggested that pyrogallol can be detected in the ethanolic extract of mango kernel (the mango tested was purchased from an Egyptian local market) with a concentration of $1337.9 \pm 0.31 \mathrm{mg} / 100 \mathrm{~g}$ mango kernel, dry weight, but it was absent in the ethanolic extract of mango peel [45]. However, we found that pyrogallol could be detected in CPWE and CPEE of TN1 with a concentration of $566 \pm 55$ and $930 \pm 90 \mathrm{mg} / 100 \mathrm{~g}$ peel weight, dry basis, respectively. We speculate the reason may be due to differences between the tested mango varieties. Structurally, $p$-hydroxybenzoic acid, gallic acid, and pyrogallol are monophenolic compounds, which exhibit antioxidant activity owing to their hydrogendonating or electron-donating properties [46]. Therefore, the high free radical-scavenging activities of CPWE and CPEE of TN1 may be attributed to the high contents of p-hydroxybenzoic acid, gallic acid, and pyrogallol. Besides phenolic compounds, previous studies reported that a synergistic effect of combinations of phytochemicals may also result in beneficial biological functions such as inhibition of proliferation of human cancer cells $[38,47]$. Thus, the synergistic effects of constituents in CPWE and CPEE of TN1 with respect to their effects on biological functions warrant further investigation. The storage stability of antioxidant agent is important with respect to its potential industrial application. Here, we evaluated the storage stability of vitamin $\mathrm{C}$, CPWE of TN1, and CPEE of TN1 by DPPH radicalscavenging assay. The test sample powders were redissolved in double-distilled water at various concentrations and the sample solutions were stored at room temperature for $1,2,4$, and 8 hours, and then the corresponding DPPH radical-scavenging activities were determined. The data presented in Figure 5(a) suggest that the well-known natural antioxidant vitamin $\mathrm{C}$ would dramatically reduce its DPPH radical-scavenging activity after $1-8$ hours' storage. However, the DPPH radicalscavenging activities in either CPWE of TN1 or CPEE of TN1 were not obviously changed after 1-8 hours' storage (Figures 5(b) and 5(c)). These findings clearly indicate that the peel extracts of mango exhibited a high storage stability in terms of antioxidant activity. Fruit polyphenols have been reported to be related to immunomodulatory and anti-inflammatory properties via in vitro and animal studies [13]. NO is an inflammatory mediator induced by inflammatory cytokines or bacterial LPS in various cell types including macrophages [48]. Samples with NO inhibitory activity thus have the potential to possess anti-inflammatory activity. CPEE and CPWE from TN1 were tested for their anti-inflammatory activities by investigating their effects on NO production in LPS-induced RAW264.7 macrophages. Neither CPEE nor CPWE obviously affected the viability of RAW264.7 cells at the $6.25-25 \mu \mathrm{g} / \mathrm{ml}$ concentrations that were tested, in the presence of $1 \mu \mathrm{g} / \mathrm{ml}$ LPS (Figure 6(a)). As shown in Figure 6(b), when RAW264.7 cells were treated with $1 \mu \mathrm{g} / \mathrm{ml}$ LPS, the NO production was increased from $3.11 \pm 0.25 \mu \mathrm{M}$ to $12.8 \pm 0.1 \mu \mathrm{M}$. Moreover, when RAW264.7 cells were treated with $1 \mu \mathrm{g} / \mathrm{ml}$ LPS in the presence of various concentrations of CPEE, it was found that NO production was significantly decreased from $12.8 \pm 0.1 \mu \mathrm{M}$ to $9.54 \pm 0.08 \mu \mathrm{M}$, whereas in the presence of various concentrations of CPWE, NO production was only slightly reduced. These results indicate that CPEE of TN1 had apparent anti-inflammatory activity, and thus it may have potential as a natural and safe agent in the protection of human health by modulating the immune system. Previous studies demonstrated that extracts with high polyphenol content exhibited high antibacterial activity [49]. As such, we evaluated the antibacterial activity of CPEE and CPWE of TN1 by the diffusion disc method. Five bacteria, three Gram-negative bacteria (E. coli, S. typhimurium, and $V$. parahaemolyticus) and two Gram-positive bacteria (S. aureus and $B$. cereus), were adopted to assess the antibacterial properties. As can be seen in Figures 7(a)-7(f), both CPEE and CPWE of TN1 exhibited antibacterial activities against the 


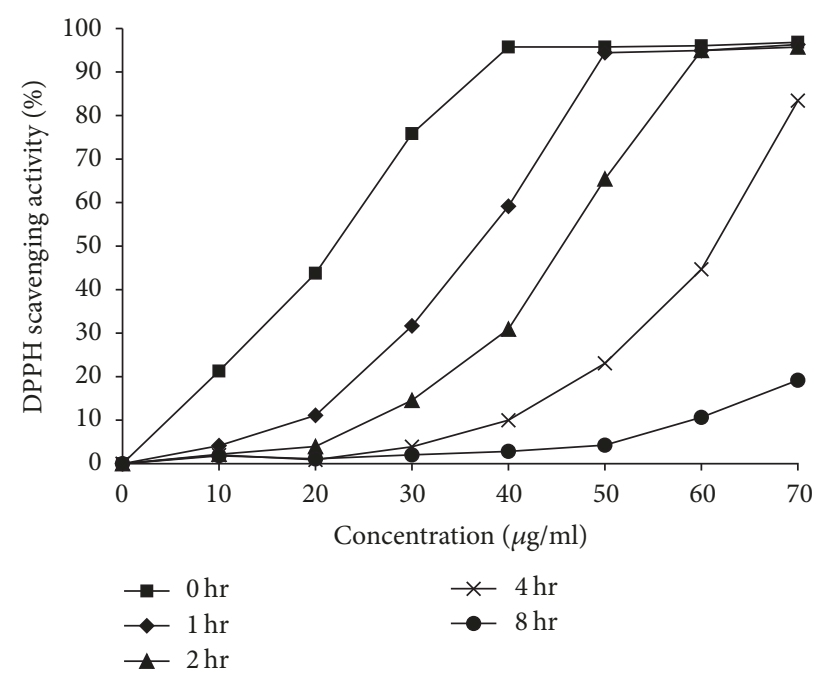

(a)

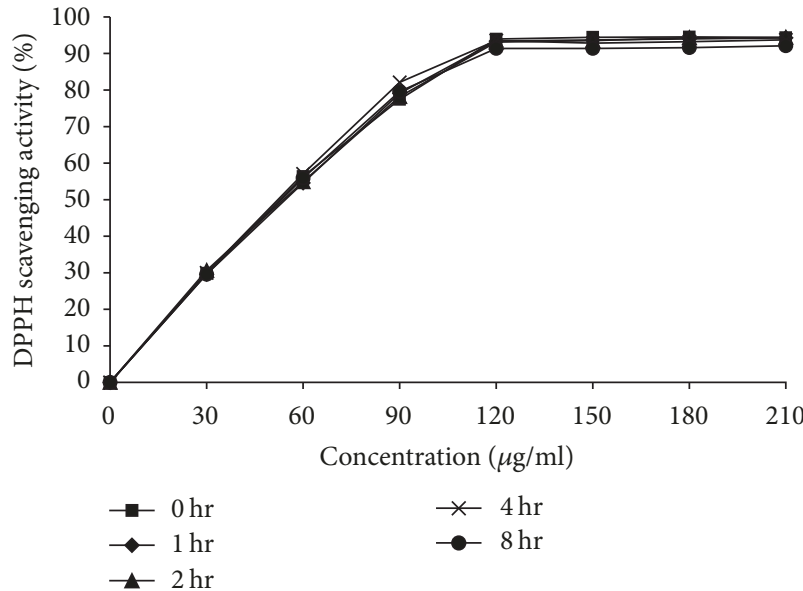

(b)

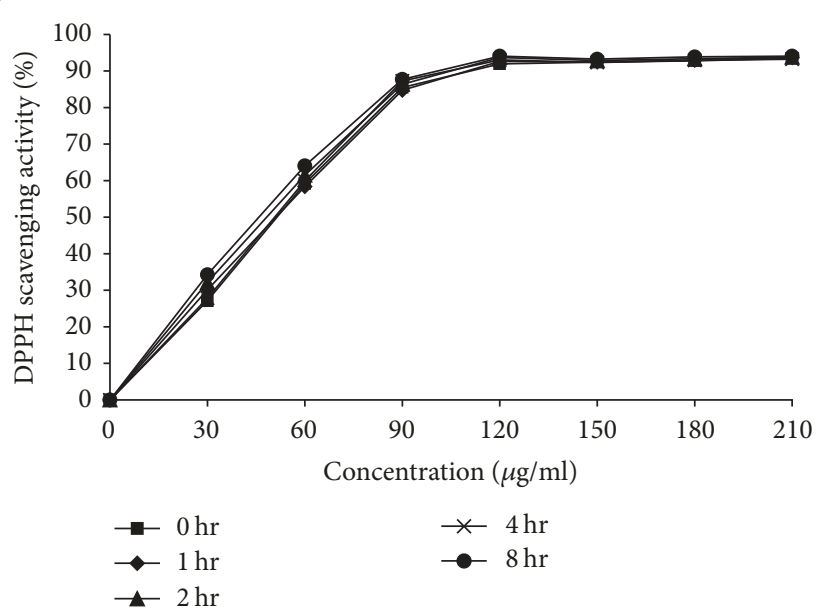

(c)

FIGURE 5: DPPH scavenging activities of vitamin C, CPWE of TN1, and CPEE of TN1 under different storage times. (a) Vitamin C; (b) CPWE of TN1; (c) CPEE of TN1.

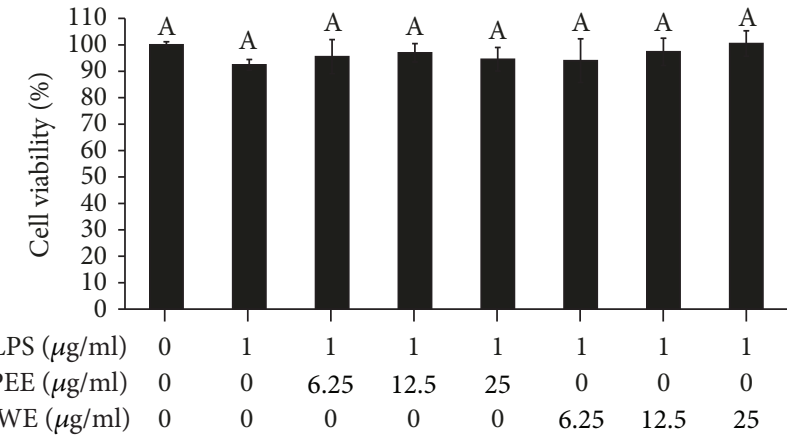

(a)

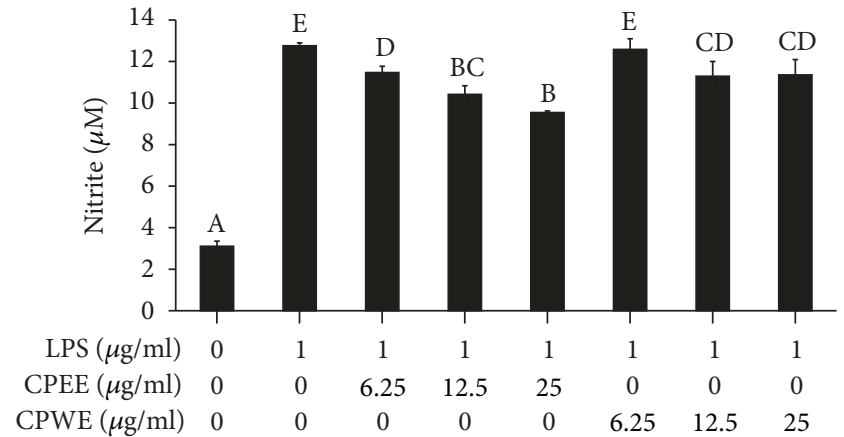

(b)

FIGURE 6: (a) Effects of CPEE of TN1, CPWE of TN1, and LPS on cell viability of RAW 264.7 cells. (b) Effects of CPEE of TN1, CPWE of TN1, and LPS on NO secretion in RAW 264.7 cells. The data are the means \pm SD of triplicate samples. Bars with different letters are significantly different $(p<0.05)$. 


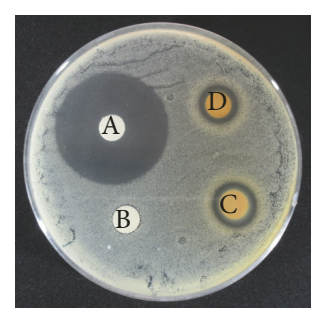

(a)

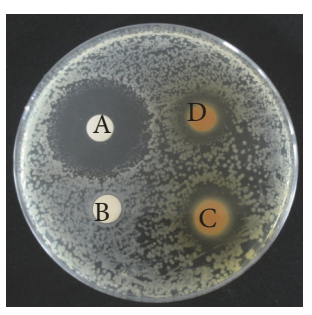

(b)

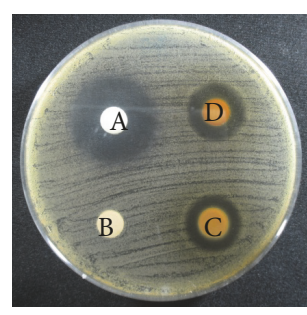

(c)

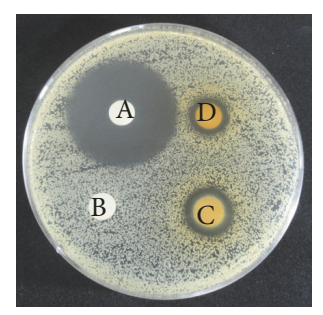

(d)

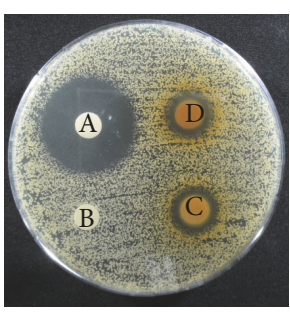

(e)

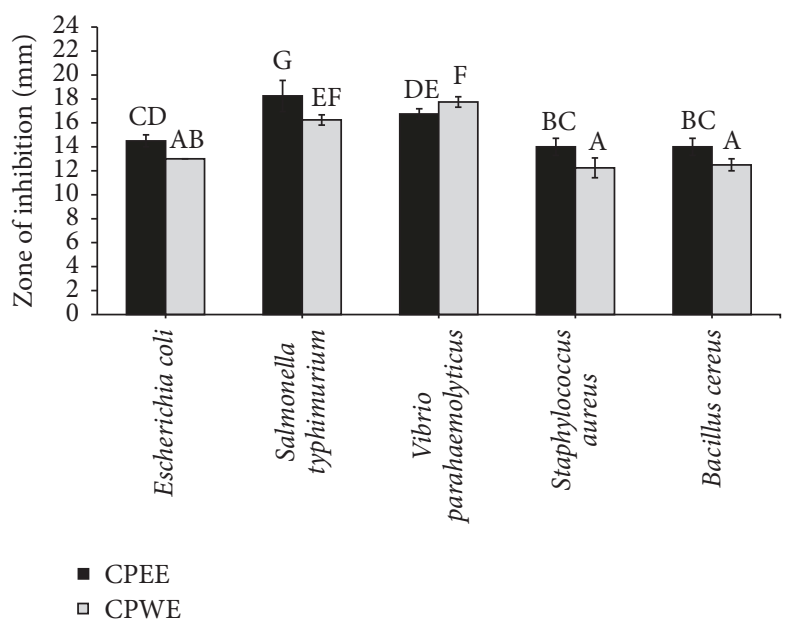

(f)

FIGURE 7: Zone of inhibition of CPEE of TN1 and CPWE of TN1 at concentration of 4\%, w/v, in $0.05 \mathrm{M}$ acetate buffer, pH 6.0, against (a) Escherichia coli, (b) Salmonella typhimurium, (c) Vibrio parahaemolyticus, (d) Staphylococcus aureus; and (e) Bacillus cereus. In each dish, A, $\mathrm{B}, \mathrm{C}$, and D represent antibiotic, acetate buffer, CPEE of TN1, and CPWE of TN1, respectively. (f) The bar graph summarizes the four separate antibacterial experiments and shows the zone of inhibition according to treatments. Values are expressed as the mean \pm SD $(n=4)$. The means that have at least one common letter do not differ significantly $(p>0.05)$.

five bacteria tested. The Gram-negative bacteria were more sensitive than Gram-positive ones to CPEE and CPWE of TN1 (Figure 7(f)). In addition, for these five bacteria, except V. parahaemolyticus, CPEE exhibited higher antibacterial activity compared to CPWE. These results may be attributed to the higher polyphenol content detected in CPEE (Table 2), which is also consistent with previous findings [50]. Interestingly, for V. parahaemolyticus, CPEE had less antibacterial activity compared to CPWE. We speculate the reason may be due to the presence of $3 \% \mathrm{NaCl}$ in the medium of $\mathrm{V}$. parahaemolyticus. However, further experimental studies are needed to elucidate the mechanism of action. In summary, the present study demonstrated that CPEE and CPWE from TN1 had high amounts of phenolic compounds, possessed good and stable free radical-scavenging activities, and exhibited anti-inflammatory and antibacterial activities. CPEE of TN1 exhibited the most antioxidant, anti-inflammatory, and antibacterial properties and thus has potential for use in the food, cosmetics, and nutraceutical industries.

\section{Conclusion}

In this study, we employed a compressional-puffing pretreatment process and two extraction methods to extract bioactive compounds from six Taiwanese mango peels. The compressional-puffing process increases the extraction yields and polyphenol contents of peel extracts. Ethanol extracts of peels had higher amounts of total phenolic compounds and greater free radical-scavenging activities as compared to water extracts of peels. The polyphenol contents of extracts positively correlated to the free radical-scavenging activities of extracts. Among these extracts, CPEE of TN1 exhibited the most antioxidant, anti-inflammatory, and antibacterial properties. Thus it is suggested as a natural, safe, and stable antioxidant agent with anti-inflammatory and antibacterial properties, which may have a wide range of applications in food, cosmetics, and nutraceuticals. Future studies on the polyphenol composition and biological activities of mango peel extracts after an in vitro digestion as well as investigations of the in vivo biological activities of mango peel extracts are warranted.

\section{Conflicts of Interest}

The authors have no conflicts of interest to declare.

\section{Authors' Contributions}

Chun-Yung Huang and Chia-Hung Kuo contributed equally to this work. 


\section{Acknowledgments}

This work was supported by a grant provided by the Ministry of Science and Technology, Taiwan, awarded to Chun-Yung Huang (no. MOST 106-2320-B-022-001).

\section{References}

[1] S. M. R. Ribeiro, L. C. A. Barbosa, J. H. Queiroz, M. Knödler, and A. Schieber, "Phenolic compounds and antioxidant capacity of Brazilian mango (Mangifera indica L.) varieties," Food Chemistry, vol. 110, no. 3, pp. 620-626, 2008.

[2] C. M. Ajila, S. G. Bhat, and U. J. S. P. Rao, "Valuable components of raw and ripe peels from two Indian mango varieties," Food Chemistry, vol. 102, no. 4, pp. 1006-1011, 2007.

[3] C. M. Ajila, K. A. Naidu, S. G. Bhat, and U. J. S. P. Rao, "Bioactive compounds and antioxidant potential of mango peel extract," Food Chemistry, vol. 105, no. 3, pp. 982-988, 2007.

[4] M. Knödler, J. Conrad, E. M. Wenzig et al., "Anti-inflammatory 5-(11'Z-heptadecenyl)- and 5-( $8^{\prime} Z, 11^{\prime} Z$-heptadecadienyl)resorcinols from mango (Mangifera indica L.) peels," Phytochemistry, vol. 69, no. 4, pp. 988-993, 2008.

[5] C. M. Ajila and U. J. S. Prasada Rao, "Protection against hydrogen peroxide induced oxidative damage in rat erythrocytes by Mangifera indica L. peel extract," Food and Chemical Toxicology, vol. 46, no. 1, pp. 303-309, 2008.

[6] A. Prakash, K. Mathur, A. Vishwakarma, S. Vuppu, and B. Mishra, "Comparative assay of antioxidant and antibacterial properties of Indian culinary seasonal fruit peel extracts obtained from Vellore, Tamilnadu," International Journal of Pharmaceutical Sciences Review and Research, vol. 19, no. 1, pp. 131-135, 2013.

[7] V. L. T. Hoang, J.-T. Pierson, M. C. Curry et al., "Polyphenolic contents and the effects of methanol extracts from mango varieties on breast cancer cells," Food Science and Biotechnology, vol. 24, no. 1, pp. 265-271, 2015.

[8] J. Mimic-Oka, D. V. Simic, and T. P. Simic, "Free radicals in cardiovascular diseases," The scientific journal Facta Universitatis Series: Medicine and Biology, vol. 6, no. 1, pp. 11-22, 1999.

[9] P. Vijayabaskar, N. Vaseela, and G. Thirumaran, "Potential antibacterial and antioxidant properties of a sulfated polysaccharide from the brown marine algae Sargassum swartzii," Chinese Journal of Natural Medicines, vol. 10, no. 6, pp. 421-428, 2012.

[10] B. Halliwell, "Antioxidants in human health and disease," Annual Review of Nutrition, vol. 16, pp. 33-50, 1996.

[11] A. L. Branien, "Toxicology and biochemistry of butylated hydroxyanisole and butylated hydroxytoluene," Journal of the American Oil Chemists' Society, vol. 52, no. 2, pp. 59-63, 1975.

[12] N. Ito, S. Fukushima, A. Hagiwara, M. Shibata, and T. Ogiso, "Carcinogenicity of butylated hydroxyanisole in F344 rats," Journal of the National Cancer Institute, vol. 70, no. 2, pp. 343352, 1983.

[13] J. González-Gallego, M. V. García-Mediavilla, S. SánchezCampos, and M. J. Tuñó, "Fruit polyphenols, immunity and inflammation," British Journal of Nutrition, vol. 104, supplement 3, pp. S15-S27, 2010.

[14] K.-J. Yun, D.-J. Koh, S.-H. Kim et al., “Anti-inflammatory effects of sinapic acid through the suppression of inducible nitric oxide synthase, cyclooxygase-2, and proinflammatory cytokines expressions via nuclear factor- $\kappa \mathrm{B}$ inactivation," Journal of Agricultural and Food Chemistry, vol. 56, no. 21, pp. 1026510272, 2008.

[15] Y.-C. Liang, Y.-T. Huang, S.-H. Tsai, S.-Y. Lin-Shiau, C.-F. Chen, and J.-K. Lin, "Suppression of inducible cyclooxygenase and inducible nitric oxide synthase by apigenin and related flavonoids in mouse macrophages," Carcinogenesis, vol. 20, no. 10, pp. 1945-1952, 1999.

[16] M. Wawruch, L. Bozekova, S. Krcmery, and M. Kriska, "Risks of antibiotic treatment," Bratisl Lek Listy, vol. 103, no. 7-8, pp. 270-275, 2002.

[17] A.-S. H. Abdullah, M. E. S. Mirghani, and P. Jamal, "Antibacterial activity of Malaysian mango kernel," African Journal of Biotechnology, vol. 10, no. 81, pp. 18739-18748, 2011.

[18] H. Kim, J. Y. Moon, H. Kim et al., "Antioxidant and antiproliferative activities of mango (Mangifera indica L.) flesh and peel," Food Chemistry, vol. 121, no. 2, pp. 429-436, 2010.

[19] J. C. Barreto, M. T. S. Trevisan, W. E. Hull et al., "Characterization and quantitation of polyphenolic compounds in bark, kernel, leaves, and peel of mango (Mangifera indica L.)," Journal of Agricultural and Food Chemistry, vol. 56, no. 14, pp. 55995610, 2008.

[20] V. S. Falcão-Silva, D. A. Silva, M. D. F. V. Souza, and J. P. Siqueira Jr., "Modulation of drug resistance in Staphylococcus aureus by a kaempferol glycoside from Herissantia tiubae (Malvaceae)," Phytotherapy Research, vol. 23, no. 10, pp. 1367-1370, 2009.

[21] C. H. Sai Srinivas, M. kumar Mediboyina, U. J. S. PrasadaRao, and A. Kothakota, "Studies on isolation and antioxidant properties of bioactive phytochemicals from mango peel harvested at different developmental stages," International Journal of Agriculture, vol. 2, no. 2, pp. 136-148, 2017.

[22] A. Kuganesan, G. Thiripuranathar, A. N. Navaratne, and P. A. Paranagama, "Antioxidant and anti-inflammatory activities of peels, pulps and seed kernels of three common mango (Mangifera indical L.) varieties in Sri Lanka," International Journal of Pharmaceutical Sciences and Research, vol. 8, no. 1, p. 70, 2017.

[23] M. N. Safdar, T. Kausar, and M. Nadeem, "Comparison of ultrasound and maceration techniques for the extraction of polyphenols from the mango peel," Journal of Food Processing and Preservation, vol. 41, no. 4, Article ID e13028, 2017.

[24] E. Dorta, M. G. Lobo, and M. González, "Improving the efficiency of antioxidant extraction from mango peel by using microwave-assisted extraction," Plant Foods for Human Nutrition, vol. 68, no. 2, pp. 190-199, 2013.

[25] R. Rojas, J. C. Contreras-Esquivel, M. T. Orozco-Esquivel, C. Muñoz, J. A. Aguirre-Joya, and C. N. Aguilar, "Mango peel as source of antioxidants and pectin: Microwave assisted extraction," Waste and Biomass Valorization, vol. 6, no. 6, pp. 1095-1102, 2015.

[26] M. P. Garcia-Mendoza, J. T. Paula, L. C. Paviani, F. A. Cabral, and H. A. Martinez-Correa, "Extracts from mango peel byproduct obtained by supercritical $\mathrm{CO}_{2}$ and pressurized solvent processes," LWT-Food Science and Technology, vol. 62, no. 1, pp. 131-137, 2015.

[27] C.-Y. Huang, S.-J. Wu, W.-N. Yang, A.-W. Kuan, and C.-Y. Chen, "Antioxidant activities of crude extracts of fucoidan extracted from Sargassum glaucescens by a compressionalpuffing-hydrothermal extraction process," Food Chemistry, vol. 197, pp. 1121-1129, 2016. 
[28] W.-N. Yang, P.-W. Chen, and C.-Y. Huang, "Compositional characteristics and in vitro evaluations of antioxidant and neuroprotective properties of crude extracts of fucoidan prepared from compressional puffing-pretreated sargassum crassifolium," Marine Drugs, vol. 15, no. 6, article no. 183, 2017.

[29] P.-S. Chiang, D.-J. Lee, C. G. Whiteley, and C.-Y. Huang, "Antioxidant phenolic compounds from Pinus morrisconicola using compressional-puffing pretreatment and water-ethanol extraction: Optimization of extraction parameters," Journal of the Taiwan Institute of Chemical Engineers, vol. 70, pp. 7-14, 2017.

[30] P.-S. Chiang, D.-J. Lee, C. G. Whiteley, and C.-Y. Huang, "Extracting antioxidant phenolic compounds from compressional-puffing pretreated Pinus morrisonicola: Effects of operational parameters, kinetics and characterization," Journal of the Taiwan Institute of Chemical Engineers, vol. 75, pp. 70-76, 2017.

[31] C.-Y. Huang, C.-H. Kuo, and P.-W. Chen, "Compressionalpuffing pretreatment enhances neuroprotective effects of fucoidans from the brown seaweed Sargassum hemiphyllum on 6-hydroxydopamine-induced apoptosis in SH-SY5Y cells," Molecules, vol. 23, no. 1, p. 78, 2018.

[32] V. L. Singleton and J. A. Rossi, "Colorimetry of total phenolics with phosphomolybdicphosphotungstic acid reagents," American Journal of Enology and Viticulture, vol. 16, pp. 144-158, 1965.

[33] A. Schieber, W. Ullrich, and R. Carle, "Characterization of polyphenols in mango puree concentrate by HPLC with diode array and mass spectrometric detection," Innovative Food Science and Emerging Technologies, vol. 1, no. 2, pp. 161-166, 2000.

[34] C.-Y. Wang, T.-C. Wu, S.-L. Hsieh, Y.-H. Tsai, C.-W. Yeh, and C.Y. Huang, "Antioxidant activity and growth inhibition of human colon cancer cells by crude and purified fucoidan preparations extracted from Sargassum cristaefolium," Journal of Food and Drug Analysis, vol. 23, no. 4, pp. 766-777, 2015.

[35] H. Kobuchi, M. T. Droy-Lefaix, Y. Christen, and L. Packer, "Ginkgo biloba extract (EGb 761): Inhibitory effect on nitric oxide duction in the macrophage cell line RAW 264.7," Biochemical Pharmacology, vol. 53, no. 6, pp. 897-903, 1997.

[36] C.-Y. Huang, C.-H. Kuo, and C.-H. Lee, "Antibacterial and antioxidant capacities and attenuation of lipid accumulation in 3T3-L1 adipocytes by low-molecular-weight fucoidans prepared from compressional-puffing-pretreated Sargassum crassifolium Sargassum crassifolium," Marine Drugs, vol. 16, no. 1, p. 24, 2018.

[37] M. R. Ali, M. J. Yong, R. Gyawali, A. Mosaddik, Y. C. Ryu, and S. K. Cho, "Mango (Mangifera indica L.) peel extracts inhibit proliferation of HeLa human cervical carcinoma cell via induction of apoptosis," Journal of the Korean Society for Applied Biological Chemistry, vol. 55, no. 3, pp. 397-405, 2012.

[38] H. Kim, H. Kim, A. Mosaddik, R. Gyawali, K. S. Ahn, and S. K. Cho, "Induction of apoptosis by ethanolic extract of mango peel and comparative analysis of the chemical constitutes of mango peel and flesh," Food Chemistry, vol. 133, no. 2, pp. 416-422, 2012.

[39] Y.-G. Liu, X.-M. Zhang, F.-Y. Ma, and Q. Fu, “The antioxidant activitives of mango peel among different cultivars," in IOP Conference Series: Earth and Environmental Science, vol. 61, Thailand, March 2017.

[40] F. Shahidi and P. K. Wanasundara, "Phenolic antioxidants," Critical Reviews in Food Science and Nutrition, vol. 32, no. 1, pp. 67-103, 1992.

[41] J. Wang, Q. Zhang, Z. Zhang, H. Song, and P. Li, "Potential antioxidant and anticoagulant capacity of low molecular weight fucoidan fractions extracted from Laminaria japonica," International Journal of Biological Macromolecules, vol. 46, no. 1, pp. 6$12,2010$.
[42] L. P. Leong and G. Shui, "An investigation of antioxidant capacity of fruits in Singapore markets," Food Chemistry, vol. 76, no. 1, pp. 69-75, 2002.

[43] S. Tachakittirungrod, S. Okonogi, and S. Chowwanapoonpohn, "Study on antioxidant activity of certain plants in Thailand: mechanism of antioxidant action of guava leaf extract," Food Chemistry, vol. 103, no. 2, pp. 381-388, 2007.

[44] A. Elzaawely and S. Tawata, "Preliminary phytochemical investigation on mango (Mangifera indica L.) leaves," World Journal of Agricultural Sciences, vol. 6, no. 6, pp. 735-739, 2010.

[45] U. E. S. Mostafa, "Phenolic compound and antioxidant potential of mango peels and kernels (Mangifera indica L.) on the frying oil stability, lipid profile and activity of some antioxidant serum enzymes in rats," Journal of American Science, vol. 9, no. 11, pp. 371-378, 2013.

[46] W. Brand-Williams, M. E. Cuvelier, and C. Berset, "Use of a free radical method to evaluate antioxidant activity," $L W T$ - Food Science and Technology, vol. 28, no. 1, pp. 25-30, 1995.

[47] N. P. Seeram, L. S. Adams, M. L. Hardy, and D. Heber, "Total cranberry extract versus its phytochemical constituents: antiproliferative and synergistic effects against human tumor cell lines," Journal of Agricultural and Food Chemistry, vol. 52, no. 9, pp. 2512-2517, 2004.

[48] E. J. Swindle and D. D. Metcalfe, "The role of reactive oxygen species and nitric oxide in mast cell-dependent inflammatory processes," Immunological Reviews, vol. 217, no. 1, pp. 186-205, 2007.

[49] K. Fukai, T. Ishigami, and Y. Hara, "Antibacterial activity of tea polyphenols against phytopathogenic bacteria," Agricultural and Biological Chemistry, vol. 55, no. 7, pp. 1895-1897, 1991.

[50] R. Naz, H. Ayub, S. Nawaz et al., "Antimicrobial activity, toxicity and anti-inflammatory potential of methanolic extracts of four ethnomedicinal plant species from Punjab, Pakistan," BMC Complementary and Alternative Medicine, vol. 17, no. 1, article no. 302, 2017. 


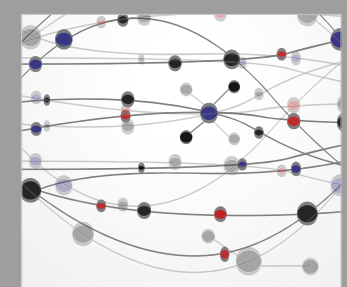

The Scientific World Journal
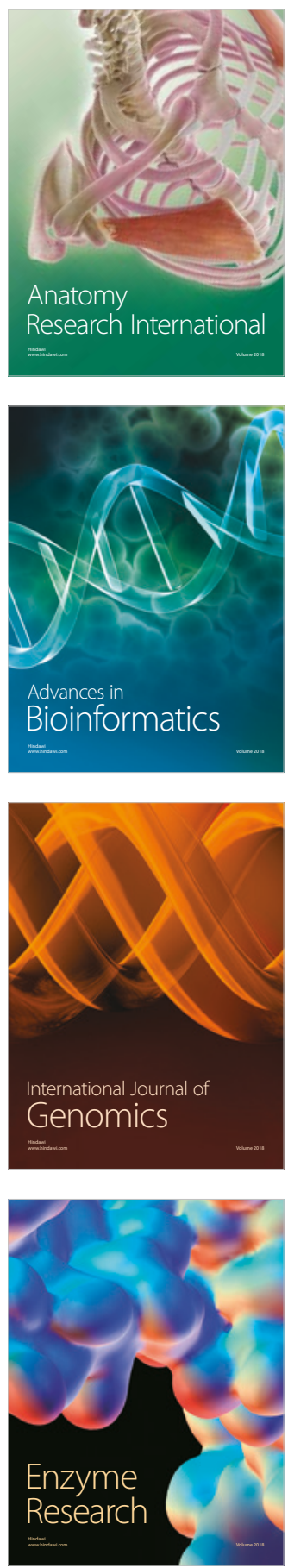
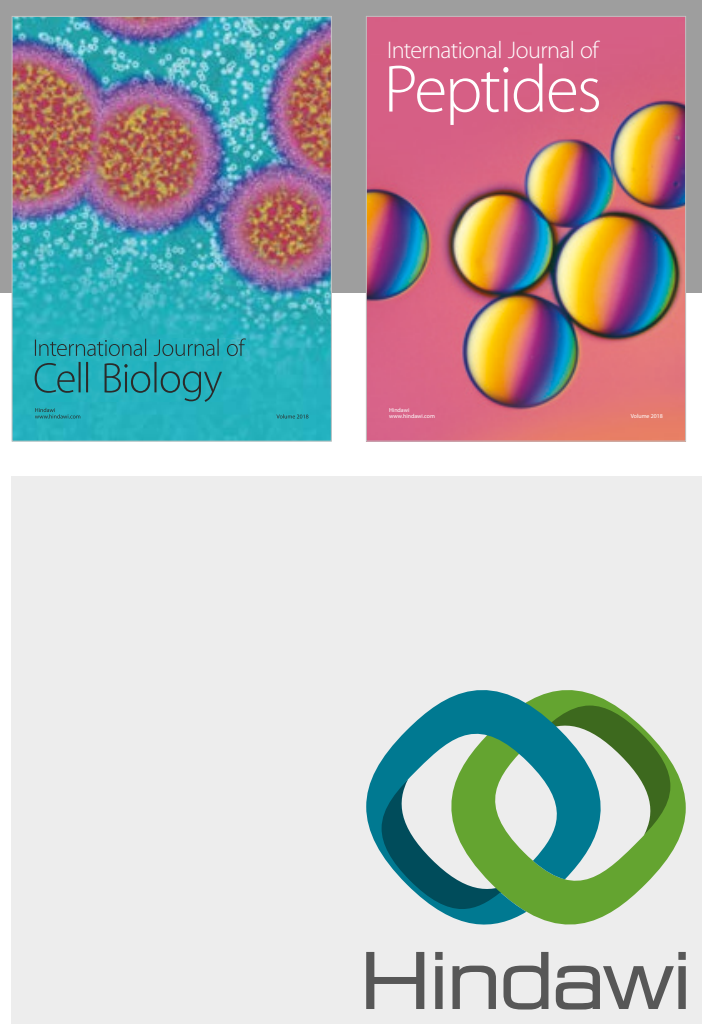

Submit your manuscripts at

www.hindawi.com
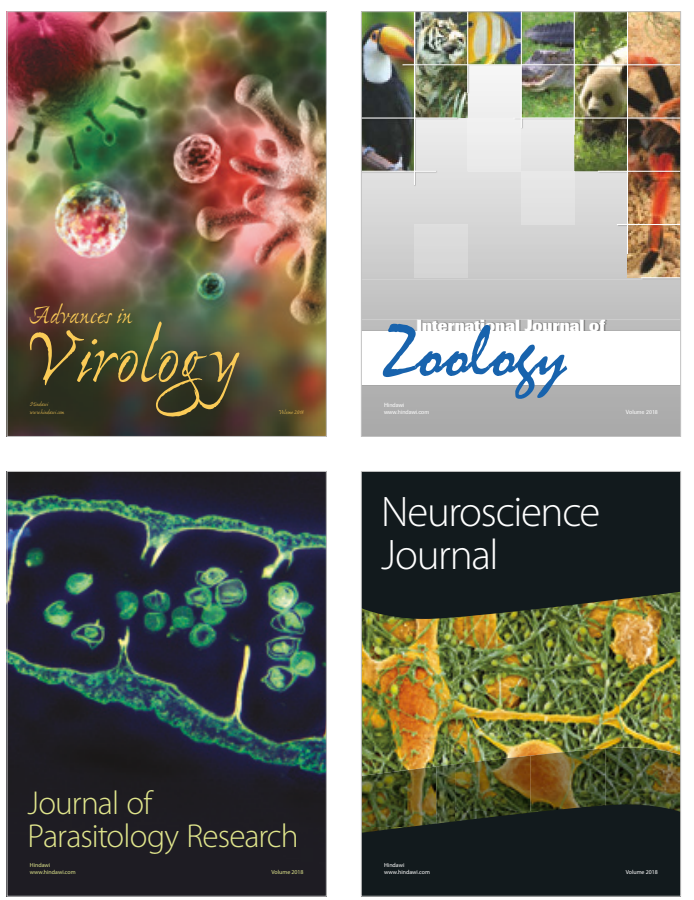
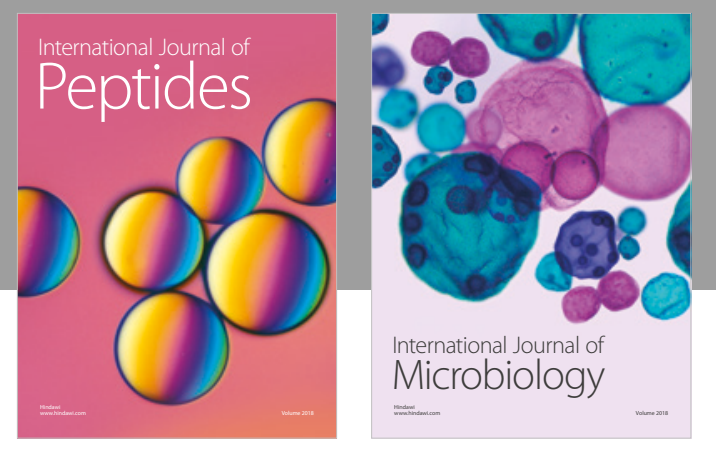

nternational Journal of Microbiology
Journal of
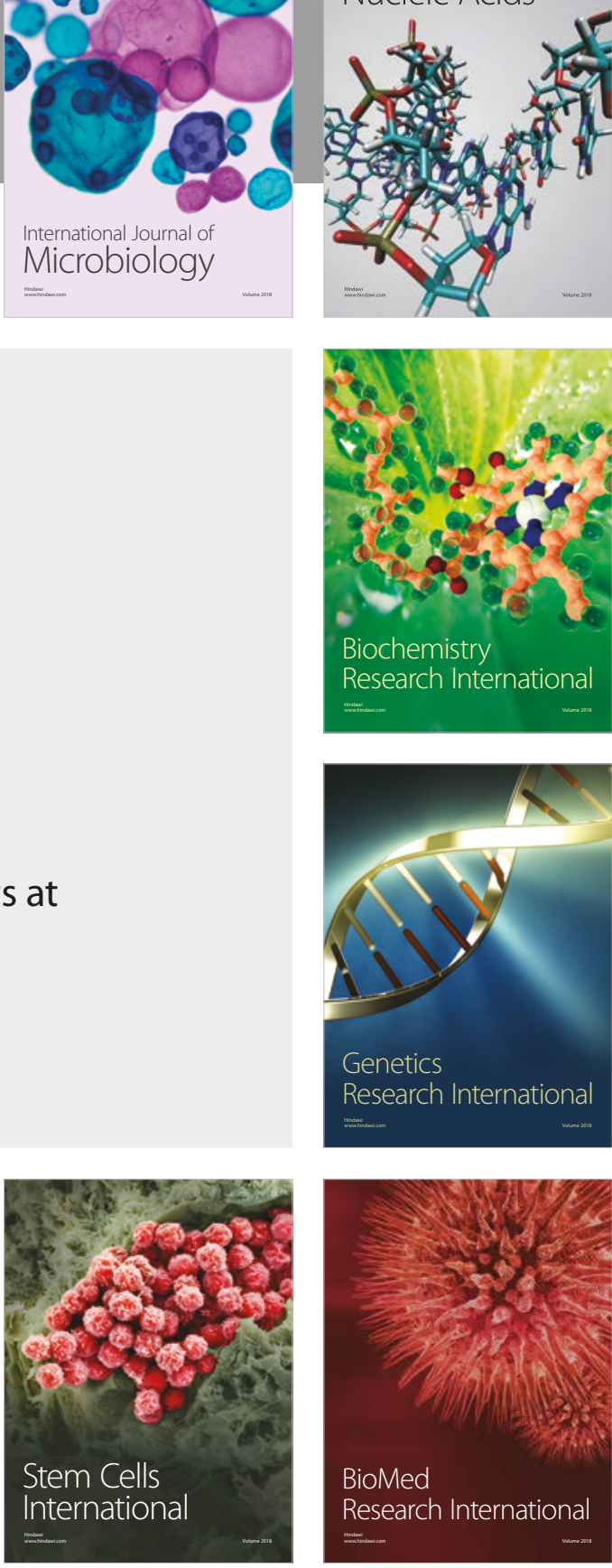
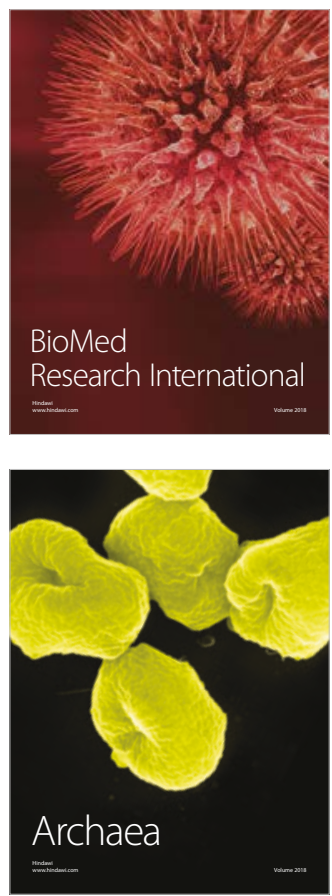